\title{
Signet-Ring Cell Carcinoma of the Urinary Bladder: A Review and Update
}

\author{
Anthony Kodzo-Grey Venyo \\ North Manchester General Hospital, Department of Urology, Manchester, M8 5RB, United Kingdom.
}

*Corresponding Author: Anthony Kodzo-Grey Venyo, North Manchester General Hospital, Department of Urology, Manchester, M8 5RB, United Kingdom.

Received date: April 26, 2021; Accepted date: May 05, 2021; Published date: May 07,2021

Citation: Anthony Kodzo-Grey Venyo. (2021) Signet-Ring Cell Carcinoma of the Urinary Bladder: A Review and Update. J.Cancer Research and Cellular Therapeutics. 5(2); Doi: 10.31579/2640-1053/081

Copyright: (C) 2021, Anthony Kodzo-Grey Venyo, This is an open access article distributed under the Creative Commons Attribution License, which permits unrestricted use, distribution, and reproduction in any medium, provided the original work is properly cited.

\section{Abstract}

Signet-ring cell carcinoma of the urinary bladder is an uncommon histopathology variant of carcinoma of urinary bladder which has been stated to account for $0.5 \%$ and $2 \%$ of primary malignant tumours of the urinary bladder. Signet-ring cell carcinoma of the urinary bladder is stated to either arise from the wall of the urinary bladder or from remnants of the urachus, or signet-ring cell carcinoma of the urinary bladder could also develop as a metastatic tumour that has ensued a primary signet-ring cell carcinoma that had arisen from a number sites of the body some of which include: the stomach, colon, or breast, the appendix and other organs. It has been iterated that the least common type of signet-ring cell carcinoma is primary signet-ring cell carcinoma and that up to 2013 less than 100 cases had been reported. Signet-ring cell carcinoma of the urinary bladder can affect males as well as females, young individuals or adults. Signet-ring cell carcinoma of the urinary bladder could be diagnosed incidentally or it may present with non-specific symptoms that simulate the symptoms of other urinary bladder tumours including: lower urinary tract symptoms, haematuria, abdominal pain / discomfort or loin pain, retention of urine, feeling unwell, or weight loss. Microscopy examination of the tumour whether it was obtained by means of trans-urethral resection or by cystectomy would tend to demonstrate a tumour that is comprised of signet-ring cells that contain peripherally pushed hyperchromatic nuclei, intra-cytoplasmic mucin, as well as lakes of extracellular mucin. The tumour cells could be arranged in lobules, and separated by fibrovascular septae. There tends to be visualization of mitosis as well as evidence of necrosis. The tumour tends to be seen within the underlying stroma and quite often within the detrusor muscle and up to the extra-vesical fat quite often. Immunohistochemistry staining studies of signet-ring cell carcinoma of the urinary bladder would tend to show tumour cells that exhibit positive staining for: Cytokeratin including cytokeratin 7 , CAM 5.2, AE1/3, and 34ßE12; Vimentin; Peanut lectin agglutinin; Ulex europaeus agglutinin. In signet ring cell carcinoma of urinary bladder immunohistochemistry staining of the tumour may also show tumour cells that exhibit positive staining for the following tumour markers: CK, CK7, CK20; CDX2; Villin - There could be a small amount of positive staining for Villin. In signet-ring cell carcinoma of the urinary bladder, immunohistochemistry studies of the tumour may demonstrate tumour cells that do exhibit negative staining for the ensuing tumour markers: Vimentin, (this does show therefore that some tumours would stain positive and others would stain negative); GATA3, and P53. To confirm whether a signet-ring cell carcinoma of the urinary bladder is a pure primary tumour or metastatic tumour does require detailed history taking with evidence of previously treated signet-ring cell carcinoma elsewhere and comparing the pathology features of the tumours, the undertaking of radiology imaging including ultrasound scan, computed tomography scan or magnetic resonance imaging scan of abdomen and pelvis as well as upper gastrointestinal endoscopy and lower gastrointestinal endoscopy to ascertain if there are any lesions within the gastrointestinal tract and taking biopsies of any suspicious lesion found for pathology examination and comparing the features of the lesions with the urinary tract tumours. There is no consensus opinion of the treatment of signet-ring cell carcinomas of the urinary bladder even though it has been realised that primary signet ring cell carcinomas have tended to be more invasive and higher staged as well as associated with very poor prognosis in comparison with the traditional urothelial carcinoma. Treatment options that have been utilized have included: trans-urethral resection of tumour, radical cystectomy alone or radical cystectomy plus adjuvant therapy and despite utilization of radical cystectomy and adjuvant therapy majority of patients tend to die. There are sporadic reports of isolated cases of good short-term, medium-term, and long-term survival usually if the tumour is diagnosed at an early stage. Early diagnosis, aggressive complete surgical excision of primary and metastatic signet-ring cell carcinomas and utilization appropriate combination adjuvant therapies would provide the best treatment of curative intent. Additionally, there is an anecdotal report of an effective treatment of an advanced metastatic primary signet-ring cell carcinoma of the urinary bladder with utilization of docetaxel which resulted in destruction of the tumour cells without an operation which would indicate that some chemotherapy agents could be good enough for the successful treatment of signet-ring cell carcinomas of the bladder including primary and metastatic tumours. Therefore, it is possible that novel treatment options of treatment of signet-ring 
cell carcinoma of the urinary bladder including an appropriate chemotherapy plus additional non-operative treatments including cryotherapy, radiotherapy, radiofrequency ablation, irreversible electroporation, selective angiography and chemical infusion of chemotherapy agents into the tumour plus immunotherapy could be explored as treatment options. There is a global need for urologists, oncologists, and pharmacotherapy research workers to identify new chemotherapy medicaments that would safely and effectively destroy primary and metastatic signet-ring cell tumours in order to improve upon the outcome of the disease. A global multi-centre trial of various aggressive treatment options should be commenced quickly.

Key Words: Signet-ring cell carcinoma; adenocarcinoma; urinary bladder; primary; metastatic; stomach; colon; histopathology; CT scan; esophagogastroduodenoscopy; colonoscopy; biopsy; radical cystectomy; chemotherapy; radiotherapy; adjuvant therapy; poor prognosis; immunohistochemistry; mucin; peripherally; Cytokeratin including cytokeratin; Vimentin; Peanut lectin agglutinin; Ulex europaeus agglutinin

\section{Introduction}

Signet-ring cell carcinoma of the urinary bladder is an uncommon histopathology variant of adenocarcinoma of the urinary bladder that tends to be characterised by the production of mucus and presence of signet-ring appearance of the tumour cells on histopathology examination of the tumours in which the nuclei of the tumour cells are pushed to the periphery of the tumour cells. Signet-ring cell carcinoma of the urinary bladder can be a primary signet-ring cell carcinoma of the urinary bladder or a metastatic signet-ring cell carcinoma with the primary signet-ring cell carcinoma originating elsewhere. With regard to metastatic signet-ring cell carcinoma of the urinary bladder, the primary tumour may have previously been treated with the metastatic urinary bladder signet-ring cell carcinoma subsequently developing, or at times the primary tumour may be contemporaneously diagnosed when the metastatic signet-ring cell carcinoma of the urinary bladder initially manifests in association with symptoms of the primary tumour or the primary tumour could be diagnosed following detailed investigations undertaken by the urologists including radiology imaging and upper and lower gastrointestinal endoscopy procedures and biopsies of lesions found during these investigations. Primary Signet ring-cell carcinoma (SRCC) of the urinary bladder is said to be a relatively uncommon subtype of adenocarcinoma which has stated been to comprise only of $0.5 \%$ to $2 \%$ of primary carcinomas of the urinary bladder [1]. Following the first case of primary signet-ring cell carcinoma of urinary bladder which had been reported in 1955 by Saphir, [2,3] sporadic cases, case series and studies on primary and metastatic signet-ring cell carcinomas of the urinary bladder have been reported in the global literature. But because of the rarity of primary and metastatic signet-ring cell carcinomas of the urinary bladder, it would be envisaged that majority of clinicians including general practitioners, urologists, and pathologists, as well as oncologists would not have encountered a case of the disease before and hence they might not be familiar with the diagnostic features, biological behaviour, management, and management outcome of the tumour. Primary signet-ring cell carcinoma of the urinary bladder does have similar histopathology examination characteristics as that of primary signet-ring cell carcinomas of the gastrointestinal tract, breast, lung, gall bladder, prostate gland, and other organs and hence further evaluations to ascertain the primary sites of these tumours have been stated to be mandatory [3]. Considering that signet-ring cell carcinoma of the urinary bladder, whether it is a primary or metastatic tumour is an uncommon tumour, it would important for clinicians to have an overview background knowledge of signet-ring cell carcinomas generally and then about signet-ring cell carcinomas of the urinary bladder in order to be up to date with the diagnosis and management of signet-ring cell carcinomas of the urinary bladder whether primary or metastatic. The ensuing article has been divided into two parts: (A) Overview which has discussed various general aspects of signet-ring cell carcinomas affecting other organs and the urinary bladder and (B) Miscellaneous narrations and discussions from some case reports, case series and studies related to signet-ring cell carcinoma of the urinary bladder.

\section{Methods}

Internet data bases were searched including: Google; Google Scholar; Yahoo; and PUBMED. The search words that were used included: Signet-ring cell carcinoma; Signet-ring cell carcinoma of bladder; primary signet-ring cell carcinoma of urinary bladder; metastatic signetring cell carcinoma of the urinary bladder; signet-ring cell carcinoma metastatic to the bladder. Forty eight references were identified which were used to write the article that has been divided into two parts: (A) Overview which has discussed various general aspects of signet-ring cell carcinomas affecting other organs and the urinary bladder and (B) Miscellaneous narrations and discussions from some case reports, case series and studies related to signet-ring cell carcinoma of the urinary bladder.

\section{Results / Review and Update of the literature on} signet-ring cell carcinoma of the urinary bladder

\section{[A] Overview}

General Overview of signet-ring cell carcinomas with emphasis on general overview of signet-ring cell carcinoma of the urinary bladder with miscellaneous discussions of signet-ring cell carcinomas of other organs.

\section{Definition and General Statements}

- $\quad$ Signet-ring cell carcinoma (SRCC) is a terminology that is utilized for an uncommon form of a generally highly malignant adenocarcinoma which does produce mucin [4].

- The diagnosis of signet-ring cell carcinoma (SRCC) has tended to be made based on histopathology examination findings of the appearance of signet-ring cells within the tumour / epithelium and on the whole if signet-ring cell component is visualized in another tumour cell type, the diagnosis of signet ring-cell carcinoma tends to be made if there are more than $20 \%$ of signet-ring cells within the tumour.

- It has been iterated that primary signet-ring cell (PSRCC) tumours has most often tended to be encountered within glandular cells of the stomach and that signet-ring cell carcinoma (SRCC) does originate within the stomach in 56 percent of patients, [5] and PRSCC has tended to be encountered less frequently in the breast, gallbladder, urinary bladder, and pancreas, [6]

- $\quad$ Sporadic cases of SRCCs have been reported in the lungs [7].

- $\quad$ SRCCs have also additionally been reported in different organs which had included the rectum, the prostate gland, the testis, the upper urinary tract, the kidney and in various other organs.

- It has been stated that with regard to colorectal carcinomas, the prevalence of SRCC has tended to be less than $1 \%$. It has also been 
documented that the incidence and mortality of carcinoma of the stomach has reduced in many countries over the preceding 50 years as well as that there has also been an increase with regard to the finding of signet-ring cell carcinomas of the stomach [8].

- It has been iterated that signet-ring cell carcinomas (SRCCs) have tended to grow in characteristic sheets and this does make the diagnosis of SRCC with utilization of standard radiology imaging including computed tomography(CT) scan, as well as PET/CT scans less effective with regard to the diagnosis of SRCCs $[9,10]$.

- Despite this statement ultrasound scan, CT scan, MRI scan, and PET/CT scan are important in identifying SRCCs, their size, and position and ultrasound scan, CT scan, and MRI scan can be utilized to identify SRCCs and they can be utilized as guidance for biopsies of some SRCCs for histopathology examination which would be utilized to establish the diagnosis of SRCCs.

- $\quad$ Signet-ring cell carcinoma of the kidney, renal pelvis and upper urinary tract, and urinary bladder can be either a primary tumour or a metastatic tumour with the primary tumour originating elsewhere.

- With regard to the causes of SRCCs, it has been iterated that some cases of SRCC have tended to be inherited by mutations within the CDH1 gene, which does encode the important cell-cell adhesion glycoprotein E-cadherin [11, 12]. It has also been documented that somatic mutations of the APC gene had also been implicated with regard to the development of SRCCs of the stomach [13].

- It has been iterated that the role of other risk factors related to the development of carcinoma of the stomach such as salt-preserved food, smoking, auto-immune gastritis, have not been well studied in signet-ring cell carcinoma [14].

- Considering that only few cases of primary and metastatic signetring cell carcinomas of the kidney, renal pelvis, and upper urinary tract have been reported, the role of risk factors that are involved in the development of SRCCs of the kidney, renal pelvis and upper urinary tract, and urinary bladder have not yet been studied extensively.

- With regard to the mechanism for the formation / development of signet ring cell carcinomas (SRCCs) the following statements have been made:

- SRCCs tend to be dedifferentiated adenocarcinomas that loose the capability for cell to cell interaction [15].

- It has been stated that highly differentiated adenocarcinomas do form SRCCs through a loss of adherens and tight junctions which typically do separate MUC4, a mucin protein, and ErbB2, an oncogenic receptor. When MUC4 and ErbB2 have the ability to interact, they have tended to trigger an activation loop. As an emanation, the ErbB2/ErbB3 signalling pathway does tend to be constitutively activated, cell to cell interactions tend to be lost and signet ring carcinomas are then formed. It has additionally been stated that constitutive action of the ErbB2/ErbB3 complex also does enhance cell growth [16].

- The mechanisms of SRCC has still remained not very well clarified; however, it had been ascertained that a carcinoma of colon cell which is referred to as HCC2998 can cause an increase in the production of differentiated tumour. It has been stated that the explanation for this increase in differentiated tumour production has been related to active PI3K which are converted to a SRCC-like cells [16].

- With regard to the development of metastases, it has been documented that the pattern of the development of metastasis is different for signet-ring cell carcinoma of the stomach in comparison with the pattern of development of intestinal type carcinoma of the stomach. Signet-ring cell carcinoma tumour has often tended to be found in the peritoneum as well as it has been known to spread through by lymphatic permeation of the lungs and to the ovaries which does create Krukenberg tumours [17].

- Additionally, reports of cases of gastric carcinomas that had metastasized to the breast and formed signet-ring cell tumour components have been published. Some authors, [18] had recommended that when signet-ring cells are identified in breast cancer, the presence of stomach cancer should be taken into consideration as a differential diagnosis.

- With regard to the histopathology examination features of signetring cell carcinomas, the terminology of signet-ring-cell carcinoma has been coined as a result of the fact that the tumours do mimic signet-ring cells, which do tend to develop from the formation of large vacuoles which are full of mucin that does displace the nucleus to the peripheral area of the cell [19].

- It has been stated that carcinomas of the stomach that contain adenocarcinoma as well as signet-ring carcinomas that are referred to as mixed-signet-ring cell carcinomas do tend to exhibit a more aggressive biological behaviour in comparison with purely signetring cell carcinoma or non-sigmoid ring cell carcinoma tumour histopathology types of tumours [20].

- A study had reported on signet-ring cell colorectal carcinomas that compared mucin-rich signet-ring cell carcinoma tumours with that of mucin-poor signet-ring cell carcinoma tumours in which the authors did conclude that the mucin-poor signet-ring cell carcinoma tumours more often had demonstrated adverse histopathology examination characteristics including lymphatic invasion, venous invasion as well as peri-neural invasion [21].

- With regard to the treatment of signet-ring cell carcinomas, it has been documented that chemotherapy has tended to be associated with a relatively poor treatment of curative intent efficacy for the management of signet-ring cell carcinomas and the over-all survival rates associated with chemotherapy for signet-ring cell carcinomas had tended to be lower in comparison with the survival rates of patients who had been treated for the more typical carcinoma pathology. It has been documented that signet-ring cell carcinomas had usually tended to be diagnosed during the later stages of the disease, at a time when the tumours are in advanced stages, such that the malignant tumours generally had tended to spread more aggressively when compared with non-signet-ring cell carcinomas, and this had tended to make treatment of signet-ring cell carcinomas more challenging [22].

- Some authors [23] had apparently iterated that in the future, case studies would suggest that development of bone metastases would likely play a bigger role with regard to the diagnosis and treatment of signet-ring cell carcinomas of the stomach.

- It has been stated that with regard to signet-ring cell carcinoma of the stomach, the undertaking of gastrectomy to remove the gastric cancer had tended to be the treatment of choice. It has also been iterated that there is no known combination of chemotherapy treatment option that has so far been proven to be superior with regard to the treatment of signet-ring cell carcinomas of the stomach in comparison with other chemotherapy treatment options; however, the most active chemotherapy options that have been used for the treatment of signet-ring cell carcinomas had included: 5-Fluorouracil (6-FU), Cisplatin, and Etoposide. Some authors [24] did report the 
use of newer chemotherapy treatment options that had included: Tamzor and Gemcitabine (Gemzar) which are under consideration.

- Some authors [25] have reported the case of an individual who had signet-ring cell carcinoma of the urinary bladder who had recurrent metastases, who had demonstrated response to treatment to palliative FOLFOX-6 chemotherapy.

- It has been iterated that reports had been published within the literature of occasional pulmonary tumour thrombotic microangiopathy that had led to pulmonary hypertension as well as coagulation problems which could be treated successfully with Imatinib

\section{Presentation}

The presentations of signet-ring cell carcinomas of the urinary bladder could include:

(a) An incidental finding.

(b) loin/flank/back/abdominal pain or discomfort

(c) Weight loss / loss of appetite

(d) Feeling unwell

(e) Other nonspecific symptoms

(f) Lower urinary tract symptoms

(g) Haematuria.

(h) Retention of urine.

\section{Clinical Examination findings}

Some of the possible clinical examination findings in cases of signet-ring cell carcinomas of the urinary bladder could include:

(a) No abnormality within the abdomen.

(b) Tenderness in the loin.

(c) suprapubic tenderness and occasionally a palpable suprapubic urinary bladder mass.

(d) If associated contemporaneously with signet-ring cell carcinoma elsewhere like the gastrointestinal tract some of the symptoms could include: nausea, vomiting, diarrhoea, abdominal distention.

(e) In cases of a previous surgical excision of a signet-ring cell carcinoma of the gastro-intestinal tract or any abdominal organ, there would be a surgical scar in the abdomen

Laboratory Investigations

Urine

- Urinalysis, urine microscopy and culture are routine tests that tend to be undertaken as part of the general assessment of individuals who have signet-ring cell carcinoma of upper urinary bladder. The results would tend to be normal but if there is any evidence of urinary tract infection it would be treated accordingly to improve upon the general condition of the individual prior to undergoing definitive surgical treatment.

- Urine cytology examination tends to be undertaken occasionally if there is evidence of a possible urinary bladder tumour but generally this would not show any malignant looking urothelial (transitional cell) carcinoma cells.

Haematology blood tests
- Full blood count, and coagulation tests tend to be undertaken as part of the general assessment of individuals who have signet-ring cell carcinoma of the urinary bladder. The results would tend to be normal but if there is any evidence anaemia it would be treated accordingly to improve upon the general condition of the individual prior to undergoing definitive surgical treatment.

\section{Biochemistry Blood tests}

- $\quad$ Serum urea, EGFR, renal function tests, blood glucose, and liver function tests tend to be undertaken as part of the general assessment of individuals who have signet-ring cell carcinoma of the urinary bladder. The results would tend to be normal but if there is any evidence of an abnormal test it would be treated accordingly to improve upon the general condition of the individual prior to undergoing definitive surgical treatment. With regard to the development of liver metastases there could be abnormal liver function test results and radiology imaging including ultrasound scan of abdomen, computed tomography scan of abdomen, and magnetic resonance imaging scan would demonstrate the liver lesions. In cases of dehydration there could be evidence of impaired renal function.

\section{Radiology Imaging \\ Chest X-ray}

- $\quad$ Chest X-ray is a general assessment that some individuals undergoing surgery for urinary bladder tumours tend to undergo as part of the general assessment of the patients especially in the developing areas of the world as well as post-operatively in combination of ultrasound scan of abdomen and pelvis in the initial staging of the disease as well as in the follow-up assessment of patients especially in areas where computed tomography scan and magnetic resonance imaging are not readily available and in some areas when where computed tomography scan and magnetic resonance imaging are available some of the patients cannot afford to pay for the cost of these newer images. Nevertheless, computed tomography scan and magnetic resonance imaging scan have replaced chest $\mathrm{x}$-ray.

\section{Ultrasound scan}

- $\quad$ Ultrasound scan of abdomen and pelvis plus ultrasound scan of renal tract would demonstrate the lesion within the renal tract as well as if there are any lesions elsewhere within the abdomen and pelvis, the ultrasound scan would show it but the features of the lesion would be nonspecific. If there is a lesion within the stomach or the gastrointestinal tract, ultrasound scan of abdomen and pelvis would not confirm this and the diagnosis of a lesion within the gastrointestinal tract would tend to be demonstrated by upper gastrointestinal intestinal tract endoscopy in cases of tumours of the stomach and oesophagus which can be biopsied for histology examination and tumours within the large bowel would tend to be demonstrated by colonoscopy and any suspicious lesion found within the large bowel would be biopsied for histopathology examination. Tumours of the appendix would however, be demonstrated by computed tomography scan and magnetic re-sonance imaging scan.

- Ultrasound scan of renal tract and pelvis / abdomen could be undertaken as part of the follow-up assessments of patients who have undergone treatment for signet-ring cell carcinoma of the urinary bladder to ascertain if they have developed any metastasis and this would tend to undertaken in less developed countries in association with chest $\mathrm{x}$-ray but this has been replaced by utilization of computed tomography / magnetic resonance imaging scan of thorax, abdomen and pelvis in well-resourced and developed countries.

\section{Computed Tomography (CT) scan}

- $\quad$ CT scan of abdomen and pelvis plus CT scan of renal tract would demonstrate the lesion within the urinary bladder as well as if there 
are any lesions elsewhere within the abdomen and pelvis, the CT scan would show it but the features of the lesion would be nonspecific. If there is a lesion within the stomach or in the gastrointestinal tract, CT scan of abdomen and pelvis would not confirm this and the diagnosis of a lesion within the gastrointestinal tract would tend to be demonstrated by upper gastrointestinal intestinal tract endoscopy in cases of tumours of the stomach and oesophagus which can be biopsied for histology examination and tumours within the large bowel would tend to be demonstrated by colonoscopy and any suspicious lesion found within the large bowel would be biopsied for histopathology examination. Tumours of the appendix would be demonstrated by computed tomography scan

- CT scan of thorax, renal tract and pelvis / abdomen and pelvis could be undertaken as part of the follow-up assessments of patients who have undergone treatment for signet-ring cell carcinoma to ascertain if they have developed any metastasis.

Magnetic Resonance Imaging (MRI) Scan

- $\quad$ MRI scan of abdomen and pelvis plus MRI scan of renal tract would demonstrate the lesion within the urinary bladder as well as if there are any lesions elsewhere within the abdomen and pelvis, the MRI scan would show it but the features of the lesion would be nonspecific. If there is a lesion within the stomach or the gastrointestinal tract, MRI scan of abdomen and pelvis would not confirm this and the diagnosis of a lesion within the gastrointestinal tract would tend to be demonstrated by upper gastrointestinal intestinal tract endoscopy in cases of tumours of the stomach and oesophagus which can be biopsied for histology examination and tumours within the large bowel would tend to be demonstrated by colonoscopy and any suspicious lesion found within the large bowel would be biopsied for histopathology examination. Tumours of the appendix would be demonstrated by computed tomography scan

- MRI scan of thorax, renal tract and pelvis / abdomen could be undertaken as part of the follow-up assessments of patients who have undergone treatment for signet-ring cell carcinoma to ascertain if they have developed any metastasis.

\section{Positron Emission Tomography / Computed Tomography Scan}

- At times PET/CT scan tends to be undertaken as part of the investigation of an individual who has primary or secondary signetring cell carcinoma of the urinary bladder in order to ascertain the extent of the disease.

Isotope Bone Scan

- Isotope bone scan tends to be undertaken at times to ascertain if an individual who has primary or metastatic signet-ring cell carcinoma of the urinary bladder has or has not developed bone metastasis.

\section{Upper Gastrointestinal Endoscopy}

In order to confirm whether or not a signet-ring cell carcinoma of the urinary bladder is a primary tumour or metastatic tumour from the gastrointestinal tract, upper gastrointestinal endoscopy and lower gastrointestinal endoscopy plus biopsy of tumours or suspicious areas of the stomach and lower bowel tend to taken for pathology examination and the features of the lesions of the urinary bladder tend to be compared with the features of biopsies obtained from the gastrointestinal tract. If an individual has previously had surgery for any previous signet-ring cell carcinoma excised from the stomach or the bowel, the old specimens always tend to be reviewed and compared with the specimens that have been obtained from the urinary bladder.

\section{Colonoscopy}

In order to confirm whether or not a signet-ring cell carcinoma of the urinary bladder is a primary tumour or metastatic tumour from the gastrointestinal tract, upper gastrointestinal endoscopy and lower gastrointestinal endoscopy plus biopsy of tumours or suspicious areas of the stomach and lower bowel tend to taken for pathology examination and the features of the lesions of the kidney / renal pelvis / upper urinary tract tend to be compared with the features of biopsies obtained from the gastrointestinal tract. If an individual has previously had surgery for any previous signet-ring cell carcinoma excised from the stomach or the bowel, the old specimens always tend to be reviewed and compared with the specimens that have been obtained from the kidney / renal pelvis / upper urinary tract.

\section{Treatment}

Treatment of signet ring cell carcinomas of the urinary bladder could include the following options:

- Trans-urethral resection of bladder tumour plus adjuvant therapy including (a) chemotherapy, plus (b) radical radiotherapy.

- $\quad$ Transurethral resection or the bladder tumour plus radiotherapy alone.

- Transurethral resection of bladder tumour plus combination chemotherapy.

- $\quad$ Radical cystectomy alone.

- Radical cystectomy plus radical radiotherapy,

- $\quad$ Radical cystectomy plus combination chemotherapy.

- $\quad$ Partial cystectomy alone

- $\quad$ Partial cystectomy plus radiotherapy

- Partial cystectomy plus combination chemotherapy

- Partial cystectomy plus radiotherapy plus combination chemotherapy

\section{Macroscopy examination features}

Macroscopy examination of a cystectomy specimen in cases of signetring cell carcinoma of the urinary could demonstrate a wellcircumscribed, firm, tumour which could occupy any part of the urinary bladder that has been involved by the tumour. The cut surface of the tumour would tend to be found to be whitish-yellow and it may be associated with focal areas of haemorrhage as well as macro-cysts. Normal urinary bladder tissue could be observed in other parts of the urinary bladder that is not involved by the tumour. The tumour may be found to be confined to the bladder in some cases but if it can also be found to have extended to or beyond the peri-vesical fat. This would be observed but the features would be non-specific and not diagnostic of the tumour therefore microscopy examination features and the immunohistochemistry staining features of the tumour are always needed to confirm the diagnosis.

\section{Microscopy examination features.}

Depending upon whether a signet-ring cell carcinoma of the urinary bladder is a pure or mixed signet-ring cell carcinoma, various microscopy examination features would be seen including: Signet-ring cell tumour cells only or signet-ring tumour cells plus other types of tumour cells including adenocarcinoma, urothelial carcinoma (transitional cell carcinoma) plus signet-ring cell tumour cells, tumour cells that contain intracellular mucin-filled vacuole displacing hyperchromatic nucleus to one side which would be indicative of signeting cell carcinoma.

\section{Immunohistochemistry}

Positive staining

In signet-ring cell carcinoma of the urinary bladder, tract, immunohistochemistry staining studies of the tumour does demonstrate tumour cells that exhibit positive staining for the following: [26] 
- Cytokeratin including cytokeratin 7, CAM 5.2, AE1/3, and 34ßE12.

- Vimentin.

- Peanut lectin agglutinin.

- Ulex europaeus agglutinin.

In signet ring cell carcinoma of urinary bladder immunohistochemistry staining of the tumour may also show tumour cells that exhibit positive staining for the following tumour markers:

- $\quad \mathrm{CK}, \mathrm{CK} 7, \mathrm{CK} 20$.

- $\quad$ CDX2.

- Villin - There could be a small amount of positive staining for Villin. Negative staining

In signet-ring cell carcinoma of the urinary bladder, immunohistochemistry studies of the tumour may demonstrate tumour cells that do exhibit negative staining for the following tumour markers:

- Vimentin, (this does show therefore in comparison with above some tumours would stain positive and others would stain negative).

- $\quad$ GATA3

- $\mathrm{p} 53$.

\section{Electron Microscopy examination features}

- Electron microscopy examination of the tumour could demonstrate the intracytoplasmic vacuoles that are related to intracellular oedema [26].

Differential Diagnoses

Some of the differential diagnoses of primary / secondary signet-ring cell carcinoma of the urinary bladder include:

- Urothelial carcinoma

- Micropapillary tumours

- Lymphoepithelioma-like cell carcinomas.

- Nested variant of urothelial carcinoma

- Sarcomatoid carcinoma.

- Pseudo-angiosarcomatous type of carcinoma.

- Squamous cell differentiation and squamous cell carcinoma.

- Clear cell carcinoma.

- Glandular differentiation tumours.

- Rhabdoid differentiated types of carcinomas.

- Signet-ring cell carcinomas that are pure tumours or they may be associated with other cell types of tumours, plasmacytoid carcinomas, tumours with pseudo-sarcomatous tumours with stromal changes.

- Metastatic signet-ring tumours with the primary tumour elsewhere including the stomach and the bowel, breast and other tumours.

Prognosis / Outcome of signet ring cell carcinomas affecting different organs

Outcome
With regard to the prognosis based upon the organ of the body affected by signet-ring cell carcinoma, it has been iterated that on the whole signetring cell carcinomas had tended to be aggressive tumours that had tended to be diagnosed at advances stages of the disease and survival of patients who have been afflicted by signet-ring cell carcinoma has generally tended to be shorter in comparison with other non-sigmoid cell carcinomas of the various organs. It has been iterated that the outcome of signet-ring cell carcinoma as well as its chemosensitivity with utilization of specific treatment regimens in majority of studies have remained controversial in view of the fact that its poor prognosis could be related to its more advanced stage at the time of diagnosis [14].

Some authors had suggested in their study that the dismal prognosis of signet-ring cell carcinoma would seem to be caused by its intrinsic tumour biology which should constitute a basis for further new research on signetring cell carcinomas [22].

\section{Urinary bladder}

- It has been stated that primary signet-ring cell carcinoma of the urinary bladder is very rare as well as the survival of patients who have been afflicted by signet-ring cell carcinoma of the urinary bladder has tended to be very poor and that signet-ring cell carcinoma of the urinary bladder does tend to occur mostly in men whose ages ranged between 33 years to 38 years. Nevertheless, a patient was reported in the literature who had undergone radical cystectomy that was ensued by combined S-1 and Cisplatin adjuvant systemic chemotherapy and who was reported to have a promising long-term survival of 90 months [27]. Additionally signet-ring cell carcinoma of the urinary bladder has been reported in a teenager [27].

\section{Colorectal signet-ring cell carcinoma}

- It has been documented that primary signet-ring cell carcinoma of the colon and rectum (PRSCCR is rare, and this has been reported with an incidence that is less than 1 percent. It has been iterated that signetring cell carcinoma of colon and rectum (PSRCCRP has tended to be associated with poor prognosis in view of the fact that symptoms associated with the disease often tend to develop late and the diagnosis of the malignancy tends to be made when the disease is at an advanced stage. It has been documented that the average five-year survival rate of individuals who had been treated previously for PSRCCR of between 20 months and 45 months [6].

- $\quad$ It has been stated that PSRCCR tends to affect younger adults with a higher likelihood of the tumour being associated with lymphovascular invasion and that it is worth realising that the overall survival rate of individuals who are afflicted by SRCCs had tended to be significantly worse in comparison with the survival rate that was associated with that of patients who had mucinous or poorly differentiated adenocarcinomas [28].

- It has additionally been iterated that with regard to advanced carcinomas of the stomach, the outcome of for individuals who SRCCs was significantly worse in comparison with that of individuals who had other histological examination feature types of tumours and that this could be explained based upon the fact that advanced SRCC carcinomas of the stomach had tended to be associated larger size of tumour, more lymph node metastatic involvement, a deeper more invasive depth of tumour, as well as more Borrmann type 4 tumour lesions in comparison with other types of tumours in comparison with other types of tumour [29].

\section{Stomach signet-ring cell carcinoma.}

- It has been stated that in comparison with adenocarcinoma of the stomach, SRCCs of the stomach had tended to occur more often in women and in younger individuals [9]. 
- Individuals who have SRCC of the stomach had had similar clinicopathological features with individuals who had undifferentiated histology features of gastric cancer. It has been reported in a recent study that individuals who had SRCC did have a better prognosis in comparison with individuals who were afflicted by undifferentiated carcinoma of stomach. Nevertheless, when the cases were narrowed down to individuals who had only advanced stage carcinoma of the stomach, it was found that individuals who had SRCC did have a worse prognosis in comparison with individuals who had other cell types of gastric cancer [30].

Kidney, renal pelvis, and upper urinary tract.

Very few cases of signet-ring cell carcinomas of the kidney, renal pelvis, and upper urinary tract have been reported so generally there would tend not be any global consensus opinion of the disease outcome. Nevertheless, a number of factors that need to be considered include the fact that generally signet-ring cell carcinomas generally tend to be associated with an aggressive biological behaviour and hence all signetring cell carcinomas of the kidney, renal pelvis, and upper renal tract should be treated aggressively. Signet-ring cell carcinomas of kidney, renal pelvis, and upper urinary tract could be either primary tumours, metastatic tumours, or carcinomas of unknown primary (CUPs). Irrespective of whether the tumour is primary, metastatic or carcinoma unknown primary source, it would be important to treat such tumours aggressively with the aim of completely excising the tumour and providing combination therapies including neo-adjuvant and adjuvant therapies which could include combination chemotherapy, immunotherapy and radiotherapy if possible. There is need for Urologists and oncologists to report cases of signet-ring cell carcinomas they encounter with long-term outcome data in order to help clinicians globally further understand the biological behaviour of such rare tumours so as to adopt a consensus opinion on the best management of the disease.

\section{Prognosis and staining for vimentin}

It is worth pointing out that positive staining for vimentin would not be diagnostic of signet-ring cell carcinomas but that it has been pointed out that the prognosis of patients who had vimentin positive gastric carcinomas was significantly $(\mathrm{P}<0.001)$ worse than the prognosis of patients who had vimentin negative gastric carcinomas. They iterated that the expression of vimentin in gastric cancer might contribute to the high invasive phenotype of gastric cancer and could represent a useful biological marker to determine the biological aggressiveness of gastric carcinoma [31].

By extrapolation, it is likely that signet-ring cell carcinomas of the kidneys, renal pelvis, and upper urinary tract that exhibit positive immunohistochemistry staining for vimentin could turn out to be more invasive tumours and tumours that portend a more aggressive type of tumour in comparison with signet-ring cell carcinomas of the kidney, renal pelvis, and upper urinary tract that exhibit negative staining for vimentin but this would need to be confirmed by the inclusion of immunohistochemistry staining for vimentin in a global multi-centre clinical study on signet ring cell carcinomas of the kidney, renal pelvis, and upper urinary tract.
In another study of signet ring cell carcinoma of the upper urinary tract immunohistochemistry staining of the tumour showed tumour cells that exhibited positive staining for the following tumour markers: [32] CK, CK7, CK20. CDX2, Villin. There was a small amount of positive staining for Villin. The study also reported negative staining for the following: [32] Vimentin, (this does show therefore in comparison with above some tumours would stain positive and others would stain negative), GATA3, and 553 .

[B] Miscellaneous narrations and discussions from some case reports, case series, and studies related to signet-ring cell carcinoma of the urinary bladder.

Boukettaya et al [33]. Reported two cases of signet-ring cell carcinoma as follows:

Case 1

A 72-year-old man had presented with intermittent painless, total, visible haematuria, urinary urgency, and pollakiuria. He did not have any significant past medical and family history. His general and systematic as well as abdominal examinations were normal. He had ultrasound scan of abdomen and pelvis and renal tract which demonstrated bilateral hydroureteronephrosis and thickening of the wall of the urinary bladder. He had cystoscopy which demonstrated a solid mass within the left side wall of his urinary bladder which was biopsied and histopathology examination of the biopsy specimen showed a proliferation of round-cell aspect of signet-ring. Immunohistochemistry staining of the specimen demonstrated positive immunohistochemistry staining for cytokeratin 7 and negative staining for cytokeratin 20. A diagnosis of signet-ring cell adenocarcinoma of the urinary bladder was made. He had computed tomography (CT) scan of abdomen and pelvis, which did not demonstrate any locoregional lymph nodes, metastases, or a primary tumour within any abdominal or pelvic organ. He underwent gastrointestinal endoscopy assessments and these did not demonstrate any primary tumour within the gastrointestinal tract. A diagnosis of primary signet-ring cell carcinoma of the urinary bladder was made. He underwent radical cystoprostatectomy. Histopathology examination of the tumour demonstrated features of a signet-ring cell adenocarcinoma that contained a colloid component which was estimated to be about $40 \%$. The tumour was reported as invasive and it had extended into the peri-vesical fat together with evidence of the tumour within the lymphatics as well as nerve sheathing (see figure 1). The surgical resection margins of the tumour were noted to be free of tumour. The tumour was staged as PT3NOM). He did not receive any adjuvant treatment. He re-presented 16 months subsequently with haematuria as well as perineal pain. He had urethroscopy which demonstrated stenosis within his anterior urethra and the site was biopsied and pathology examination showed features that confirmed the diagnosis of recurrence of signet-ring cell carcinoma within the urethra. He underwent radiotherapy to the tumour and the urinary bladder area (pelvis). He underwent clinical and radiology imaging follow-up assessments every 6 months during which he had computed tomography can of his thorax, abdomen, and pelvis. At his 3-years followup assessment, he had continued to have a good quality of life as well as radiology image stability. 


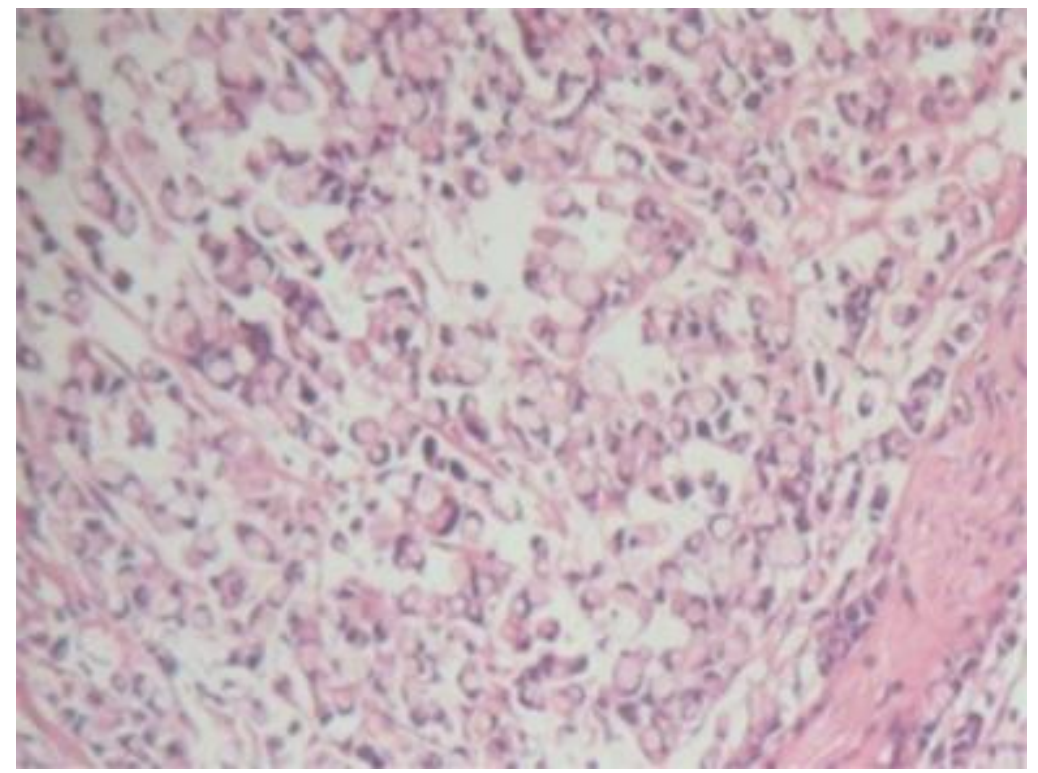

Figure 1: Histopathology of the bladder lesion showing multiple signet-ring cells (haematoxylin-eosin x200). Reproduced from: [33] Boukettaya W, Feki J, Charfi S, Toumi N, Khanfir A, Boudawara T, Daoud J, Frikha M. Primary Signet Ring Cell Adenocarcinoma of the Urinary Bladder: A Report of 2 Cases. Urology Case Reports. 2014 May; 2(3): 85 - 87.

https://www.sciencedirect.com/science/article/pii/S2214442014000473\#: :text=Primary\%20signet\%20ring\%20cell\%20carcinoma\%20of\%20the $\% 20$ urinary,often\%20poor\%2C\%20given\%20the\%20advanced\%20stage\%20at\%20diagnosis https://doi.org/10.1016/j.eucr.2014.03.004Get rights and content Under a Creative Commons license

\section{Case 2}

A 64-year-old man who did not have any significant past medical history had presented with a 2-month history of total visible haematuria. He had ultrasound scan of renal tract and pelvis which demonstrated an infiltrating mass within the posterolateral wall of his urinary bladder as well as left hydroureteronephrosis. He underwent cystoscopy which revealed a polypoid mass upon the left posterior-lateral urinary bladder. Trans-urethral resection of the urinary bladder tumour (TURBT) was undertaken. Pathology examination of the urinary bladder tumour chips demonstrated features of a poorly differentiated invasive signet-ring cell carcinoma of the urinary bladder. He had computed tomography scan of abdomen which demonstrated a large effusion which had occupied his entire abdomen and as well as peritoneal cavity with no CT scan evidence of peritoneal carcinomatosis. He underwent gastroduodenoscopy and colonoscopy which did not demonstrate presence of any suspicious lesion. The evolution of the disease process was marked by the development of ascites. Aspirate of the peritoneal fluid was examined by cytology assessment and this confirmed presence of neoplastic cells (see figure 2). Palliative chemotherapy was discussed but this could not be administered in view of his deterioration and he died 5 months pursuant to the diagnosis of his malignant tumour.

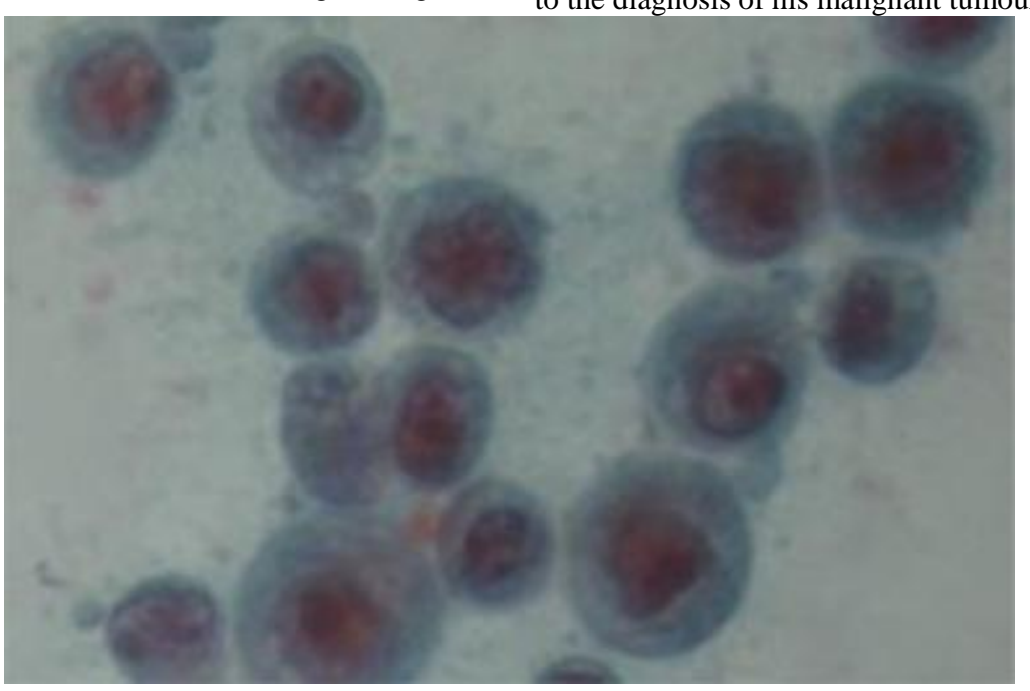

Figure 2: Neoplastic cells in the ascitic fluid. Reproduced from: [33] Boukettaya W, Feki J, Charfi S, Toumi N, Khanfir A, Boudawara T, Daoud J, Frikha M. Primary Signet Ring Cell Adenocarcinoma of the Urinary Bladder: A Report of 2 Cases. Urology Case Reports. 2014 May; 2 (3): 85 - 87. https://www.sciencedirect.com/science/article/pii/S2214442014000473\#: :text=Primary\%20signet\%20ring\%20cell\%20carcinoma\%20of\%20the\%20 urinary,often\%20poor\%2C\%20given\%20the\%20advanced\%20stage\%20at\%20diagnosis https://doi.org/10.1016/j.eucr.2014.03.004Get rights and content Under a Creative Commons license 
Akamatsu et al. [34] undertook a comprehensive review and analysis of the clinical characteristic of primary signet-ring cell carcinoma of the urinary bladder cases that had been reported within Japan. They reviewed all articles that had been reported from Japanese institutions regardless of their language. Overall they had identified 131 titles that had been reported between 1981 and 2008. They excluded meeting abstracts, but the unpublished cases within their institution were included. In all they comprehensively reviewed 54 cases and analysed them. Akamatsu et al. [34] summated their results as follows:

- The median age at the time of the initial diagnosis was 61.2 years and this was associated with a male to female dominance of $2: 1$.

- Among the selected cases, $46 \%$ of the cases did have stage IV tumours.

- The overall survival at 2-years was found to be $43 \%$. Nevertheless, none of the patients who had stage IV tumours at the time of their initial diagnosis were alive after 2 years.

- Multi-variate analysis did demonstrate that the stage of the tumour and carcinoembryonic antigen (CEA) levels did represent significant factors of prognostication.

- With regard to the 8 patients who had been followed-up for longer than 2 years and who did not develop any evidence of recurrence of tumour, 7 of them had undergone either radical cystectomy or partial cystectomy.

Akamatsu et al. [34] made the following conclusions:

- Even though the overall prognosis of primary signet-ring cell carcinoma of the urinary bladder is poor, the prognosis of the tumour is dependent upon the stage of the tumour at the time of the initial diagnosis of the tumour.

- With early diagnosis and early treatment of the tumour, it could be possible to achieve long-term survival of the patients.

Considering that Akamatsu et al. [34] had found out that the prognosis of high-staged IV primary signet-ring cell carcinomas is poor, it would be argued that academic oncologists, urologists, and pharmacotherapy research workers should endeavour to find new chemotherapy medications that would effectively and safely destroy primary signet-ring cell tumours of the urinary bladder in order to improve upon the survival and quality of life of the patients.

Bouhajja et al. [35] reported two patients who were aged 53 years in the case of a man, and 70 years in the case of a woman. They manifested with right back pain, burning upon micturition, and visible haematuria. They had ultrasound scan of abdomen, which demonstrated a thickened urinary bladder wall that measured $8 \mathrm{~mm}$ with regard to thickness. The ultrasound scan did reveal a budding intravesical lesion with a calculation of the left lower ureter that measured $5 \mathrm{~mm}$ in its greatest diameter. They underwent cystoscopy which demonstrated an atypical tissular lesion that that was frayed whitish and solid upon the cut surface. The woman had magnetic resonance imaging (MRI) scan of the pelvis which demonstrated a cervix ill-limited tissue mass that had invaded her anterior vaginal wall. Transurethral resection of the urinary bladder tumour (TURBT) was undertaken with regard to one case, and a biopsy of the urinary bladder lesion was undertaken in the other case. Immunohistochemistry staining study of tumours showed that tumour cells of both tumours had exhibited positive staining for CK7. Based upon the features of the tumours, a diagnosis of signet-ring cell carcinoma of the urinary bladder was made in each case. Bouhajjia et al. [35] made the following conclusions:
- $\quad$ Signet-ring cell adenocarcinoma the urinary bladder is an aggressive tumour that is associated with rapid development and poor prognosis.

- The management of primary signet-ring cell carcinoma of the urinary bladder tends to be multi-disciplinary and does involve, surgery.

- Utilization of adjuvant chemotherapy should be discussed even if consensual attitude had not been established.

Additionally, it would be argued that since it is known that muscle invasive signet-ring cell carcinomas of the urinary bladder tend to be associated with aggressive biological behaviour and poor prognosis ensuing in death, it would be important to treat such tumours aggressively and that a global multi-centre trial of various treatments including (a) radical cystectomy plus (b) adjuvant radiotherapy, plus (c) adjuvant combination chemotherapy, plus immunotherapy should be considered in all cases.

Hamakawa et al. [36] reported a53-year-old Japanese man, who presented with pain on voiding as well as visible haematuria for many months. He did not have any significant past medical history and he was treated with a course of antibiotics for a presumed urethritis which did not resolve his symptoms. He had urinalysis which showed red blood cells 50-99 / high power fields, and white blood cell count of 10 to 19 per high power field but there was no growth of bacteria in his urine, as well as his urine cytology was negative. The results of his serum tumour markers that included carcinoembryonic antigen were all within normal limits. $\mathrm{He}$ underwent cystoscopy which demonstrated widely prevalent nonpapillary raised lesions as well as oedematous mucosa upon the posterior wall of the urinary bladder. He had computed tomography (CT) scan of pelvis which showed marked diffuse thickening of the wall of his urinary bladder with no evidence of pelvic lymph node enlargement. He also had magnetic resonance imaging (MRI) scan which showed results that were similar to the results of his CT scan. Furthermore, sagittal MRI scan demonstrated thickening of the wall of his urinary bladder from the anterior wall to the posterior wall of the urinary bladder (see figure 3 ). Trans-urethral resection biopsy was undertaken and histopathology microscopy examination of the biopsy specimen showed signet-ring cell carcinoma with poorly differentiated adenocarcinoma. He next underwent gastroscopy, colonoscopy as well as radionuclide scanning in order to exclude an extra-vesical primary site of the tumour. Based upon the negative findings of the gastroscopy, colonoscopy and the radionuclide scanning a final diagnosis of signet-ring cell carcinoma of urinary bladder (SRCCU) was made. He underwent radical cystectomy with pelvic lymph node dissection and ileal neo-bladder construction. Macroscopy examination of the excised specimen demonstrated diffuse thickening of the wall of the urinary bladder and oedematous mucosa of the urinary bladder with reddened as well as erosive areas. Microscopy histopathology examination of the specimen demonstrated diffuse infiltration of tumour cells, abundant formation of mucin, with positive staining for periodic acid-Schiff, resulting in compression of the nucleus, which is a typifying feature of signet-ring cell tumour that had invaded the layer of a serous membrane as well as vessel invasion which was reported as a high-grade, pT3bN0M0 v(+) tumour (see figure 4). He received adjuvant combination chemotherapy with $\mathrm{S}-1$ and cisplatin. $\mathrm{He}$ did receive $S-1(80 \mathrm{mg} / \mathrm{m} 2$, on days 1 to 14 , and cisplatin $70 \mathrm{mg} / \mathrm{m} 2$ on day 8 for 3 cycles. He has continued to be well and he was alive at his 90 months post-operative follow-up assessment with no evidence of local tumour recurrence or metastasis. 


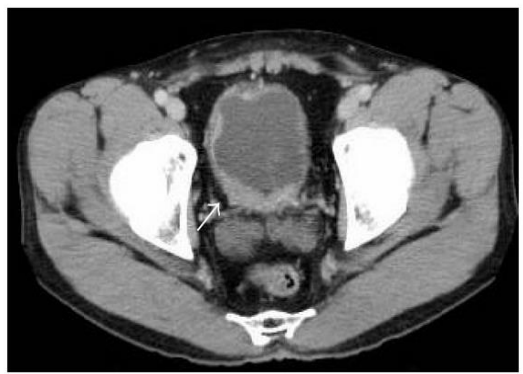

Figure 3 (a)

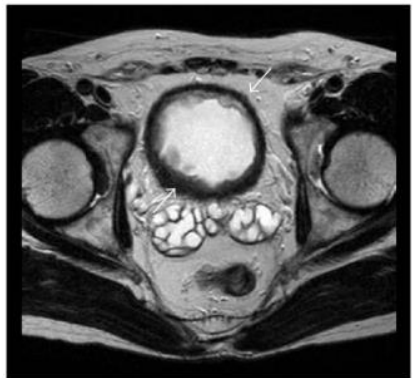

Figure 3 (b)

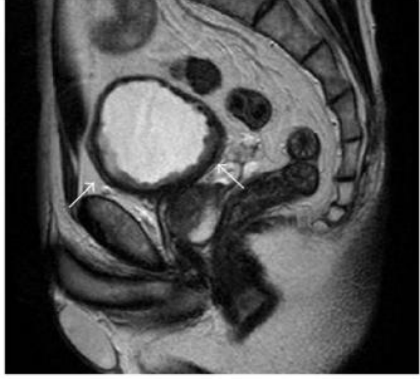

Figure $3(\mathbf{c})$

Figure 3 (a): CT shows diffuse tumour of the urinary bladder wall. (b) Transverse section of MRI demonstrates near-circumferential urinary bladder wall thickening. (c) Sagittal section of MRI shows urinary bladder wall thickening from anterior to posterior wall. Reproduced from: [36] Hamakawa T, Kojima Y, Naiki T, Kubota Y, Yasui T, Tozawa K, Hayashi Y, Kohri K. Long-term survival of a patient with invasive signet-ring cell carcinoma of the urinary bladder managed by combined s-1 and Cisplatin adjuvant chemotherapy. Case Rep Urol. 2013; 2013:915874. doi:

10.1155/2013/915874. Epub 2013 May 8. PMID: 23738191; PMCID: PMC3664482. https://pubmed.ncbi.nlm.nih.gov/23738191/ under Copyright @ 2013 Takashi Hamakawa et al.

This is an open access article distributed under the Creative Commons Attribution License, which permits unrestricted use, distribution, and reproduction in any medium, provided the original work is properly cited.

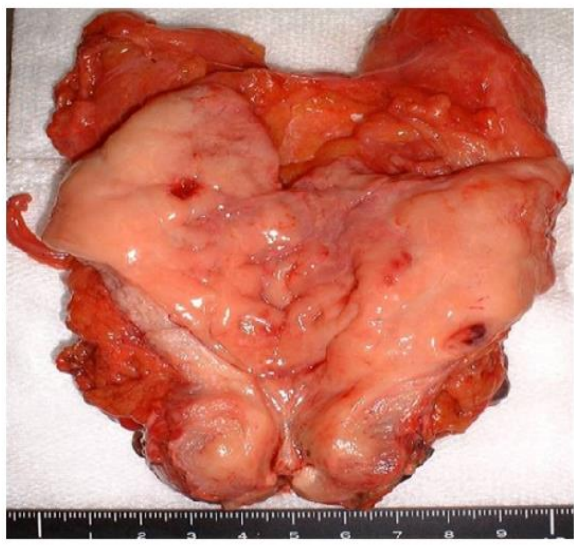

Figure (a)

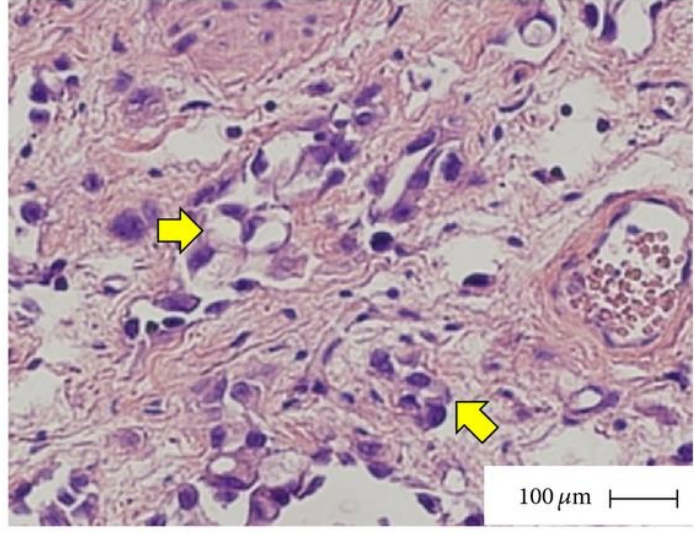

Figure 4 (b)

Figure 4 (a) macroscopic image of resected urinary bladder specimen shows white coloured, diffuse, non-papillary tumour. (b) Microscopic appearance of the urinary bladder tumour shows poorly differentiated adenocarcinoma with multiple signet-ring cells (arrow) (H\&E, high-power view). Reproduced from: [36] Hamakawa T, Kojima Y, Naiki T, Kubota Y, Yasui T, Tozawa K, Hayashi Y, Kohri K. Long-term survival of a patient with invasive signet-ring cell carcinoma of the urinary bladder managed by combined s-1 and Cisplatin adjuvant chemotherapy. Case Rep Urol. 2013; 2013:915874. doi: 10.1155/2013/915874. Epub 2013 May 8. PMID: 23738191; PMCID: PMC3664482.

https://pubmed.ncbi.nlm.nih.gov/23738191/ under Copyright @ 2013 Takashi Hamakawa et al.

This is an open access article distributed under the Creative Commons Attribution License, which permits unrestricted use, distribution, and reproduction in any medium, provided the original work is properly cited.

Wang et al. [37] undertook a study to directly compare the cancer-specific survival of patients who had signet-ring cell carcinoma (SRCC) of the urinary bladder with patients who had urothelial carcinoma (UC) of the urinary bladder. Wang et al. [37] identified patients who had a diagnosis of SRCC of the urinary bladder and urothelial carcinoma (UC) of the urinary bladder, in the Surveillance, epidemiology, and end results programme (SEER) (2001-2004). They compared the demography of the patients and the clinical characteristics of the patients at the time of their initial diagnosis. They compared the differences in the cancer-specific survival with utilization of univariate and multivariate analysis. Wang et al. [37] summated the results as follows:
- $\quad$ They had identified a total of 103 patients who had SRCC and 14,648 patients who had UC.

- $\quad$ Patients who had SRCC were younger ( $\mathrm{P}<0.001)$, and they more commonly manifested with higher-grade histology ( $\mathrm{P}<0.001)$, as well as advanced stage disease $(\mathrm{P}<0.001)$, in comparison with patients who had urothelial carcinoma (UC) of the urinary bladder.

- The three-year cancer-specific survival rate was $67.0 \%$ for patients who had urothelial carcinoma (UC) of the urinary bladder and $33.2 \%$ for patients who had signet-ring cell carcinoma (SRCC) of the urinary bladder.

- On multi-variate analysis, an increased mortality risk was found with patients who had signet-ring cell carcinoma (SCRCC) in comparison with patients who had urothelial carcinoma (UC) of the urinary bladder (HR 1.49, 96\% CI 1.11-2.00, P<0.01). 
Wang et al [37]. Made the following conclusions:

- Even after adjusting for demographic, surgical, as well as pathological factors, the cancer-specific survival rate was significantly worse with regard to patients who had signet-ring cell carcinoma (SRCC) in comparison with patients who had urothelial carcinoma (UCC) of the urinary bladder.

- Further research into the biology of this uncommon tumour would be required to explain these results.

Based upon the findings and recommendation of Wang et al [37]. it would be argued that there is an urgent need for the establishment of a global multi-centre treatment trials of various aggressive treatment options for the management of primary signet-ring cell carcinomas of the urinary bladder (PSRCCUB) that would include radical cystectomy plus neoadjuvant/adjuvant combination chemotherapy, plus radical radiotherapy, plus immunotherapy in order to find a way to improve upon the survival and prognosis of patients who have primary signet-ring cell carcinoma of the urinary bladder (PSRCCUB) as well as there is need for academic urologists, academic oncologists, and academic pharmacotherapy research workers to undertake research work that would identify newer more effective chemotherapy medicaments that would safely destroy signet-ring carcinoma cells in order to improve upon the survival and prognosis of patients who have signet-ring cell carcinoma of the urinary bladder.

Grignon et al. [38] reported 12 cases of signet-ring cell carcinoma of the urinary bladder they had collected within their institution. They summarised the results of their analysis of various aspects of the tumours as follows:

- The median age of the ten men and the two women who had signetring cell carcinoma was 58 years and the most frequent manifestation was haematuria.

- With regard to two of nine cases cystoscopy did not reveal any visible mucosal lesion.

- Eleven of the tumours were noted not to be of urachal origin and one tumour was of urachal origin.

- At the time of the initial diagnosis of the tumour, one tumour was staged as stage B, two tumours were staged as stage $\mathrm{C}$, and seven tumours were staged as stage $\mathrm{D}$, as well as with regard to two tumours the stage of the tumour was not known.

- Nine out of the 12 patients were noted to have died of their signetring cell carcinoma (within a range of 1 month to 16 months and the median time of death was 9 months), 1 patient was alive with metastases, 1 patient was alive and well, as well as 1 patient had died because of an unrelated cause.

- They had undertaken a review of the literature that included 35 cases that met their inclusion criteria to which they had added their 12 cases and they undertook statistical analysis on various aspects of the total of 47 cases. With regard to the results, they had found the following:

- The prognosis was worse with regard to a pure disease in comparison with a mixed signet-ring cell carcinoma $(\mathrm{P}=0.004)$ and for nonurachal versus urachal origin signet-ring cell carcinoma tumour $(\mathrm{P}=$ 0.005).

- The difference in the five-year survival rates between stages $\mathrm{B}$ signet-ring cell carcinoma of the bladder and stage D signet-ring cell carcinoma (P less than 0.005) was also found to be statistically significant.
The finding of Grignon et al. [38] that signet-ring cell carcinomas of the urinary bladder are aggressive tumours that are associated with aggressive biological behaviour as well as poor prognosis should be a pivot for academic urologists, oncologists, and pharmacotherapy research workers to urgently undertake research projects that are aimed at finding new treatment options that would improve the prognosis of the disease.

El Ammari [39] reported a 51-year-old Moroccan Berber man who had presented with visible haematuria. He had ultrasound scan as well as computed tomography scan which demonstrated a urinary bladder tumour which had diffusely invaded his urinary bladder wall. He underwent cystoscopy which demonstrated non-papillary sessile tumours that had occupied almost the entire wall of the urinary bladder as well as the left side of the trigone and it had also obstructed the left ureteric orifice. Incomplete trans-urethral resection of the bladder tumour was undertaken. Histopathology examination of the resected bladder tumour chips demonstrated poorly differentiated mucin-secreting adenocarcinoma of the signet-ring cell type. He underwent gastrointestinal endoscopy as well as analysis of tumour markers which did exclude an extra-vesical primary signet-ring cell tumour site. A diagnosis of primary signet-ring cell carcinoma of the urinary bladder was made. He underwent radical cystectomy plus bilateral pelvic lymphadenectomy plus ileal conduit construction. Histopathology examination of the specimen demonstrated features of an adenocarcinoma which was comprised of signet-ring cells with an abundant mucin pool which had invaded the peri-vesical adipose tissue as well as one lymph node that measured less than $2 \mathrm{~cm}$ for which the tumour was staged as $\mathrm{T} 3 \mathrm{bN} 1 \mathrm{M} 0$. He received adjuvant chemotherapy with 4 cycles of cisplatin, $100 \mathrm{mg} / \mathrm{m} 2$ on day 1 and Gemcitabine 1000 $\mathrm{mg} / \mathrm{m} 2$ on days 1 and 8 combination, every 21 days. Eighteen months pursuant to his radical cystectomy, he manifested with pelvic and back pain. He had computed tomography (CT) scan of thorax, abdomen and pelvis, which demonstrated multiple metastases within the spine, lung and pelvis. He refused to be enrolled into any additional treatment protocol and he died 4 months later because of respiratory failure. El Ammari et al. [39] concluded that the rarity and the successful treatment with carboplatin and Gemcitabine as adjuvant chemotherapy in primary signetring cell carcinoma which had been rarely reported within the literature are two characteristics which had been described in their reported case. Considering that despite an apparently good initial response to radical cystectomy and combination chemotherapy which was followed by the development of multiple metastases and death of the patient in less than 2 years due to the tumour, it would be argued that perhaps radical cystectomy plus adjuvant combination chemotherapy alone is not enough for the treatment of such an aggressive tumour and for this reason clinicians should consider the addition of radical radiotherapy plus immunotherapy as additional treatments to radical cystectomy and combination chemotherapy and these treatments should be commenced early.

Jin et al. [40] iterated that even though signet-ring cell carcinoma of the urinary bladder is a highly malignant tumour, it often tends to be neglected in view of the rarity of the tumour. Jin et al. [40] utilized the National Surveillance, Epidemiology, and End Results (SEER) data base (2004 - 2016) to compare signet ring cell carcinoma (SRCC) of the bladder with urothelial carcinoma (UC) of the bladder and they investigated the prognostic values of the clinicopathological features and survival outcomes in signet-ring cell carcinoma (SRCC) of the urinary bladder. Jin et al. [40] utilized Multi-variable Cox proportional hazard model, sub-group analyses, and propensity score matching (PSM). Jin et al. [40] summarized their results as follows:

- In all, 318 patients who had signet-ring cell carcinoma (SRCC) and 57,444 patients who had urothelial carcinoma (UC) were enrolled in their study. 
- In comparison with patients who had urothelial carcinoma (UC), patients who had signet-ring cell carcinoma were found to be younger, at the time of the initial diagnosis of the disease $(\mathrm{P}<0.001)$, and they had higher rates of muscle-invasive disease $(\mathrm{P}<0.001)$, lymph node metastases $(\mathrm{P}<0.001)$, and distant metastases $(\mathrm{P}<$ $0.001)$, as well as high-grade $(\mathrm{P}=0.004)$.

- A Cox proportional hazard regression analysis did show that the signet-ring cell carcinoma (SRCC) group was associated with significantly higher risks of overall mortality (OM) in comparison with the urothelial carcinoma (UC) group with hazard ratios (HR) = $1.44,95 \%$ confidence intervals $(95 \% \mathrm{CI})=1.26-1.63, \mathrm{P}<0.0001$.

- $\quad$ Patients who had signet-ring cell carcinoma (SRCC) also did have a higher risk of cancer-specific mortality $(\mathrm{CSM} ; \mathrm{HR}=1.40,95 \% \mathrm{CI}$ $=1.18-1.65, \mathrm{P}<0.0001)$.

- $\quad$ After PSM, the signet-ring cell carcinoma (SRCC) group also did experience higher risks of $\mathrm{OM}(\mathrm{HR}=1.45,95 \% \mathrm{CI}=1.24-1.68, \mathrm{P}$ $<0.0001)$ and $\operatorname{CSM}(\mathrm{HR}=1.47,95 \% \mathrm{CI}=1.20-1.79, \mathrm{P}=0.0001)$ in comparison with the urothelial carcinoma group.

- Within the sub-group analyses, no significant interactions were found in sex, age, $\mathrm{N}$ stage, $\mathrm{M}$ stage, and lymph nodes removed in terms of overall mortality (OM) and cancer-specific mortality (CSM).

Jin et al. [40] made the following conclusions:

- The prognosis of signet-ring cell carcinoma (SRCC) is poorer in comparison with urothelial carcinoma (UC), even following adjustment for baseline demographic and clinicopathological characteristics as well as treatment of the cancer.

- $\quad$ Signet-ring cell cancer (SRCC) is an independent prognostic factor for patients who have urinary bladder cancer.

Considering that the study of Jin et al. [40] is a recent study, it would be argued that up to date clinicians globally have not found treatment options that would drastically reduce death rates related to signet-ring cell carcinomas of the urinary bladder and for this reason it would be important for a global consensus opinion group on signet-ring cell carcinoma of the urinary bladder to be established so they can deliberate on aggressive treatment options that could improve the prognosis of the disease.

Singh et al. [41] reported a 62-year-old man who had presented with visible haematuria over the preceding 4 months. He had a CT scan of abdomen which showed an $8.0 \times 2.5 \mathrm{~cm}$ hypoechoic solid mass within the dome of his urinary bladder which had extended into his peri-vesical fat, with no evidence of loco-regional lymph nodes, metastases, or primary tumour within the abdominal or pelvic organs. Trans-urethral resection biopsy of the urinary bladder tumour was undertaken and pathology examination of the specimen showed mucinous adenocarcinoma with signet-ring cell features. Partial cystectomy and bilateral lymph node dissection was undertaken. Macroscopy examination of the specimen demonstrated the primary tumour was covered by thick mucus. The microscopy histopathology examination features of the tumour were consistent with the diagnosis of poorly differentiated mixed mucinous and signet-ring cell adenocarcinoma with high mitotic activity of greater than 10 mitotic figures per 10 high power fields as well as areas of necrosis. The tumour was found within the lamina propria beneath an intact urothelial epithelium of the bladder with a close surgical resection margin of $1 \mathrm{~mm}$ to $3 \mathrm{~mm}$ and microscopic invasion into the peri-vesical fat. Five lymph nodes were negative. A urachal remnant could not be identified. Immunohistochemistry staining of the tumour demonstrated that the tumour cells had exhibited positive staining for CK 7, CK 20, CDX-2, E- cadherin, CEA, EMA, p53, B-catenin (nuclear stain), and Villin. The tumour cells exhibited negative staining for thrombomodulin, TTF-1, PSA and WT-1. Proliferation index (Ki-67) was light. Electron microscopy examination of the tumour demonstrated core filamentous rootlets and mucus vacuoles within the signet-ring cells. Molecular testing was negative for microsatellite instability. Upper gastrointestinal endoscopy was undertaken which was normal but colonoscopy was not undertaken. He had computed tomography scan of the abdomen and pelvis which did not demonstrate a colorectal primary tumour. Many months pursuant to his partial cystectomy procedure, he developed a fistula through an ulcerated lesion on his lip under the vermillion line which did present as pain and difficulty with eating. He had biopsy of the lower lip lesion and pathology examination of the specimen showed a tumour which had features that were similar to the features of his urinary bladder tumour. He furthermore, had computed tomography (CT) scan of abdomen which showed progressive disease within the region of the duodenal bulb, within the pancreas, anterior to his right kidney, and on both sides of his residual urinary bladder. He had an endoscopic ultrasound-scan guided fine-needle aspiration biopsy of the pancreatic mass and pathology examination of the specimen did confirm metastatic signet-ring cell carcinoma. Chemotherapy that comprised of Capecitabine $1000 \mathrm{mg}$ per $\mathrm{m}^{2}$ daily for 14 days and oxaliplatin $130 \mathrm{mg} / \mathrm{m} 2$ once every 3 weeks was commenced 8 months pursuant to his partial cystectomy. He received radiotherapy to his lips at 9 months pursuant to his partial cystectomy. For the duration of his radiotherapy, oxaliplatin was withheld, but concomitant capecitabine was administered at a reduced dose. Seven (7) months pursuant to the commencement of his chemotherapy, he had radiology imaging which demonstrated stable disease within the area of the thickening on the left lateral aspect of the residual urinary bladder, as well as regression of the low attenuation areas within the right renal pelvis region, neck of the pancreas, as well as within the para-duodenal region. There was additionally almost complete resolution of the lesion on the lip and the fistula with significant improvement of his symptoms. He continued to have stable disease for 16 months before he developed progression of the tumour to his chest that became apparent. He did receive second line chemotherapy that consisted of capecitabine and irinotecan but the tumours did not respond to this treatment. He subsequently died about 24 months after the commencement of his chemotherapy. Singh et al. [41] made the ensuing concluding iterations:

Their case had raised a number of pertinent points including:

- $\quad$ Signet-ring cell carcinoma (SRCC) of the urinary bladder is very rare as well as it is important to exclude signet-ring cell carcinoma (SRCC) metastatic to the urinary bladder, or which had invaded into the urinary bladder from an adjacent organ, particularly, in an apparently early stage disease when aggressive treatment is planned.

- There does not appear to be a definite immune-profile which does clearly differentiate primary signet-ring cell carcinoma (SRCC) from signet-ring cell carcinoma (SRCC) which had secondarily involved the urinary bladder.

- $\quad$ Based upon their reported case and literature review, signet-ring cell carcinoma (SRCC) is a cancer that has a tendency to metastasize to unusual sites.

- $\quad$ Their reported case does not support the contention that signet-ring cell carcinoma (SRCC) of the urinary bladder is a treatment-resistant cancer. With regard to otherwise fit patients who have a advanced disease and who wish to undergo systemic treatment, a trial of a combination of oxaliplatin and fluoropyrimidine does appear reasonable as well as radiotherapy to symptomatic sites must be taken into consideration. 
A lesson learnt from this case report is that primary signet-ring cell carcinoma of the urinary bladder is an aggressive carcinoma that is associated with poor prognosis and death of patients and in view of this when a primary signet ring-cell carcinoma of the urinary bladder is encountered it should be treated aggressive as treatment of curative intent and it could be argued that with regard to the reported case a radical cystectomy plus pelvic lymph node dissection plus combination adjuvant therapy including radical radiotherapy, combination chemotherapy plus immunotherapy should be considered an option of aggressive treatment to use rather than to wait till metastases develop.

Andreva et al. [42] reported a case of signet-ring cell carcinoma of the urinary bladder in a 26-year-old patient. Pathology examination of the urinary bladder tumour demonstrated a poorly differentiated carcinoma of the urinary bladder which was mainly signet-ring cell type with mucosal ulceration, and deep infiltrative growth which had involved the tissues around the urinary bladder. This short summation is important in that it has illustrated that signet-ring cell carcinoma which is an aggressive tumour can also affect young adults.

Matsuzaki et al. [43] reported a 59-year-old man who manifested with non-visible haematuria. He had cystoscopy which showed a white nonpapillary tumour. He underwent trans-urethral resection of the tumour and pathology examination of the resected tumour demonstrated signet-ring cell carcinoma as well as transitional cell carcinoma with a histological death of invasion PT1. He did not receive any adjuvant therapy. Lessons that need to be learnt from this summation include the fact that signet-ring cell carcinoma of the urinary bladder can exist with transitional cell carcinoma and on rare occasions this rare malignant tumour could be found to be non-muscle invasive as demonstrated by invasion of the lamina propria only.

Ozeki et al. [44] reported a 58-year-old man who presented with visible haematuria and urinary urgency. He underwent cystoscopy which demonstrated multiple non-papillary broad based tumours as well as reddish unstable urinary bladder mucosa. He had trans-urethral resection biopsy of the urinary bladder tumours and pathology examination of the specimens demonstrated signet-ring cell carcinoma predominantly and adenocarcinoma transforming into signet-ring cell carcinoma partially. He underwent total cystectomy with ileal conduit urinary diversion. Histopathology examination of the cystectomy specimen showed grade 3 transitional cell carcinoma in association with adenocarcinoma. Ozeki et al. [44] were of the opinion that these findings did suggest that adenomatous metaplasia of transitional cell carcinoma within the urinary bladder could differentiate into signet-ring cell carcinoma.

Allameh et al. [45] reported an 18-year-old Afghan male who had a past medical history of cystolithotomy seven years earlier, who had presented with a one year history of intermittent visible haematuria with amorphous blood clots. He had ultrasound scan of renal tract and abdomen which showed non-uniform decrease in the parenchyma of both kidneys as well as bilateral hydronephrosis which was dominant in the left side (Grade III) as well as partial defect on the left urinary bladder wall. He had contrast-enhanced computed tomography (CT) scan which showed bilateral hydronephrosis which was dominant on the left side; nonuniform decrease in the cortex of both kidneys as well as multiple filling defects were demonstrated within the lumen of the urinary bladder without evidence of distant metastasis (see figure 5). He underwent transurethral resection of urinary bladder tumour which on gross visualization was noted to be a white, calcified, sessile tumour which had extended from the left side of the urinary bladder wall to the dome and the tumour had obstructed his left ureteric orifice. Trans-urethral resection of the bladder tumour (TURBT) was undertaken and left nephrostomy insertion was undertaken. The specimens was sent for polymerase chain reaction for assessment to evaluate for tuberculosis, in view of the fact that tuberculosis, is widespread in Afghanistan, Diffuse urethral stricture, nonpapillary mass, as well as diffuse erythema results were all negative. Histopathology examination of the specimen showed features that were consistent with poorly differentiated mixed mucinous and signet-ring cell adenocarcinoma. Immunohistochemistry staining studies of the tumour demonstrated that the tumour cells had exhibited strong positive staining for CK7, CK 20, and CDX-2, as well as the tumour cells had exhibited negative staining for PSA, CK34ßE12, as well as for Vimentin. The provisional differential diagnoses included (a) primary urinary bladder adenocarcinoma and (b) metastatic adenocarcinoma from a tumour which primarily originated from the gastrointestinal tract. He underwent esophagogastroduodenoscopy and recto-sigmoidoscopy which were normal. He also had normal tumour marker levels of CA 19-9, and CA 125 which excluded possible extra-vesical primary lesions. He also had trans-rectal biopsies of the prostate gland and pathology examination of the specimens were normal in that no malignant lesion was found in the samples of the prostate gland. He underwent radical cystectomy plus prostatectomy sparing the seminal vesicle and prostate preservation and orthotopic urinary diversion with "W" ileum pouch plus pelvic lymphadenectomy to the bifurcation of the aorta and bilateral ureteric stents were inserted. Gross examination of the cystectomy specimen demonstrated an ill-defined ulcerative as well as necrotic tumour mass that had soft as well as gelatinous consistency that filled the cavity of the entire urinary bladder wall that measured $2.5 \mathrm{~cm}$ with regard to its maximum thickness. Microscopic examination of the tumour showed that the urinary bladder wall was infiltrated into deep muscularis propria by a necrotic tumour which comprised of lakes of mucins that contained floating nests or cords of epithelioid cells as well as many signet-ring cells (see figure 6(a) and figure 6(b). Microscopy examination of the specimen did not demonstrate any remnant of the urachus. A final diagnosis of signet-ring variant of mucinous adenocarcinoma of the urinary bladder was established. No metastatic lymph node was identified so the tumour was staged T2NOM0 signet-ring cell carcinoma of the urinary bladder of the mucinous adenocarcinoma variant. At his six months post-operative follow-up assessment, the results of his clinical examination, chest $\mathrm{X}$ rays, computed tomography (CT) scans and cystoscopy were all normal which had indicated there was no local recurrence of tumour or distant metastasis.

A lesson that has been learnt from this case report is the fact that primary signet-ring cell carcinoma can also affect the younger the age group including teenagers and clinicians need to have a high index of suspicion for such a rare and aggressive tumour. Considering that primary signetring cell carcinoma of the urinary bladder is a very aggressive tumour, it would be argued that the option of radical cystectomy plus combination adjuvant therapies including chemotherapy, radiotherapy as well as immunotherapy should be considered as treatment options to provide treatment of curative intent. 


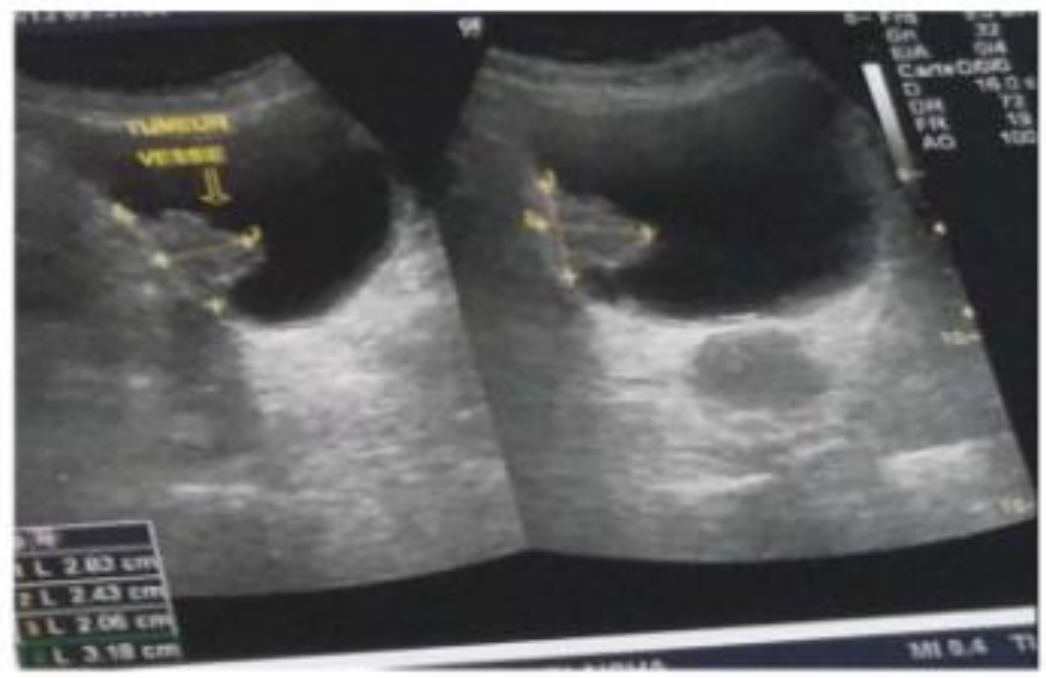

Figure 5: Bladder ultrasound showing a hyperechoic image of the right lateral wall. Reproduced from: [45] Allameh F, Karkan M F, Nilipour Y, Rakhshan A. Primary Signet-Ring Cell Carcinoma of the Urinary Bladder Successfully Managed with Radical Cystectomy in a Young Patient. Case Reports in Urology. Volume 2017; Article ID 9121078 https://doi.org/10.1155/2017/9121078

https://www.hindawi.com/journals/criu/2017/9121078/ under the creative commons attribution license.

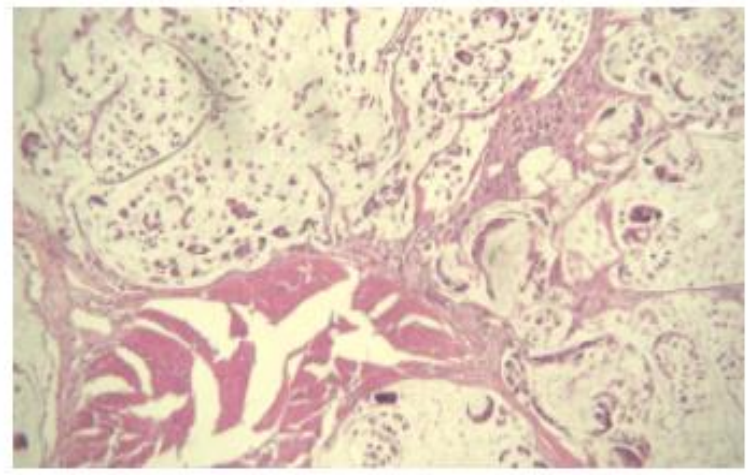

Figure 6 (a)

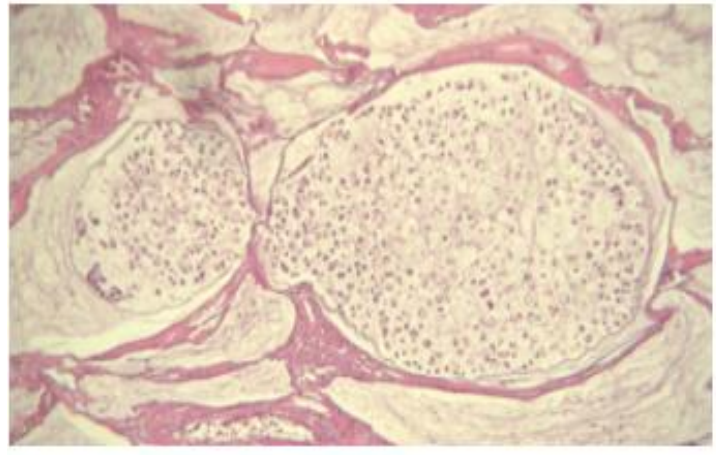

Figure 6 (b).

Figure 6 (a) and (b). Haematoxylin and Eosin stain: Tumour was mainly composed of mucin lakes cotaining cords and nests of the tumour cells and and some lakes bearing only signet-ring cells. Original magnification: x200 in (a) and x400 in (b). Reproduced from: [45] Allameh F, Karkan M F, Nilipour Y, Rakhshan A. Primary Signet-Ring Cell Carcinoma of the Urinary Bladder Successfully Managed with Radical Cystectomy in a Young Patient. Case Reports in Urology. Volume 2017; Article ID 9121078 https://doi.org/10.1155/2017/9121078

https://www.hindawi.com/journals/criu/2017/9121078/ ] Under the Creative Commons Attribution License.

Armache et al. [46] reported a 66-year-old man who presented with painless visible haematuria over the preceding one month. He had ultrasound scan of the pelvis which demonstrated a thickening of the wall of his urinary bladder. He had a computed tomography (CT) scan of abdomen and pelvis which did not show any obvious urinary bladder mass or distant metastases; however, only a diffuse thickening of the urinary bladder wall associated with bilateral enlargement of the inguinal and iliac lymph nodes (see figure 7). He had cystoscopy which demonstrated multiple sessile tumours within his left bladder wall, base and dome of the bladder. He underwent trans-urethral resection of the bladder tumour. Histopathology examination of specimens of the resected bladder tumour demonstrated features that were consisten with the diagnosis of a signetring cell carcinoma of the urinary bladder sub-type of adenocarcinoma that had infiltrated the lamina propria and muscularis (stage pT2). He underwent gastroduodenoscopy and colonoscopy as well as his CEA tumour marker levels were determined and all these investigations were normal and had excluded a primary tumour site within the gastrointestinal tract. Based upon the results of the investigations, a diagnosis of primary signet-ring cell carcinoma of the urinary bladder was made. He underwent radical cystoprostatectomy with an ileal conduit and bilateral pelvic lymph adenectomy. A frozen pelvis was found during the operation. Pathology examination of the radical cystectomy specimen revealed features of a poorly diffrentiated adenocarcinoma of the urinary bladder which had comprised of signet-ring cells that contained an abundant mucin pool with invasion of the peri-veical fat (see figure 8). The right ureteral margin was free of tumour even though the left ureteric margin was initially focally reached by the tumour. The histopathology staging of the tumour was pT3bN1M0. Immunohistochemistry staining studies of the tumour did show that the tumour cells had exhibited positive staining for Cytokeratin 7, CEA, and CA 19-9 and the tumour cells exhibited negative staining for CD-X2 (see figure 9). He received six cycles of adjuvant chemotherapy that consisted of carboplatin and Gemcitabine cobination, but he died six month later from a heart attack. 


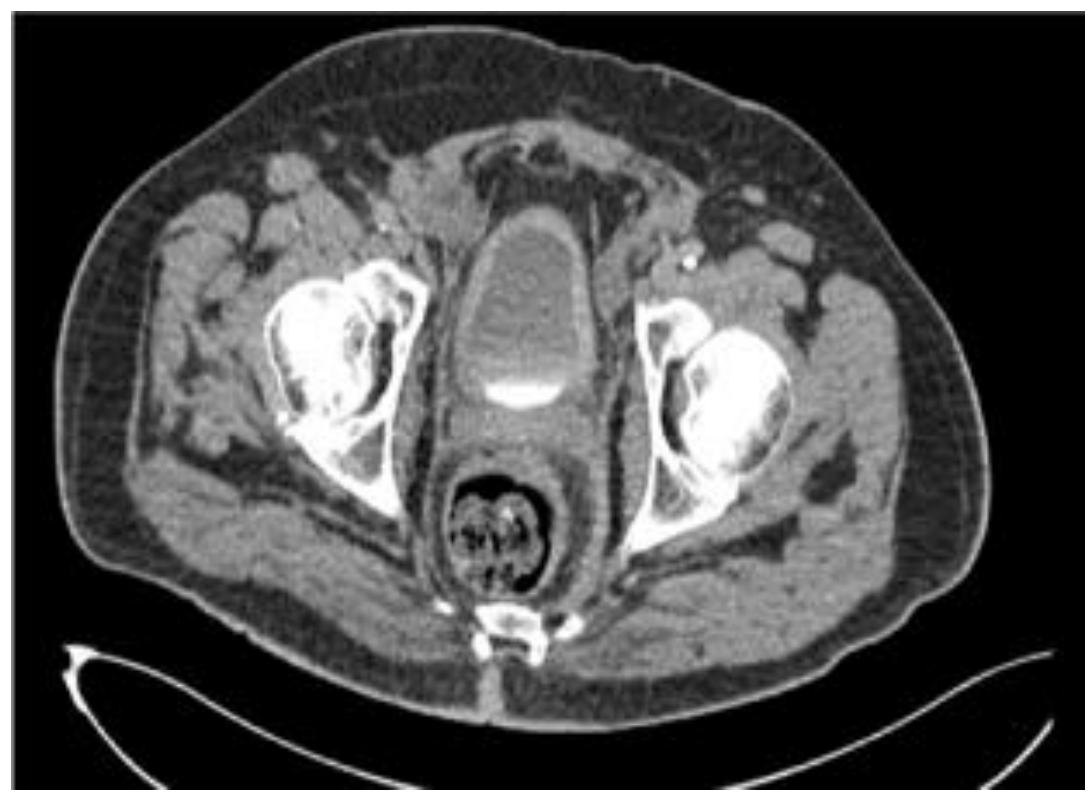

Figure 7: Abdominopelvic computed tomography showing a diffuse thickening of the urinary bladder. Reproduced from: [46] Armache K, Feghali J, Bourgi A, Chemaly A K, Aftinos G, Moukarzel M. Pure primary signet ring cell carcinoma of the bladder: atypical case and review of the literature. Urology \& Nephrology Open Acces Journal. 2014;1(3): 70 - 72. DOI:10.1504/unoaj.2014.01.00016

https://medcraveonline.com/UNOAJ/pure-primary-signet-ring-cell-carcinoma-of-the-bladder-atypical-case-and-reviewof-the-literature.html under Creative Commons Attribution License.

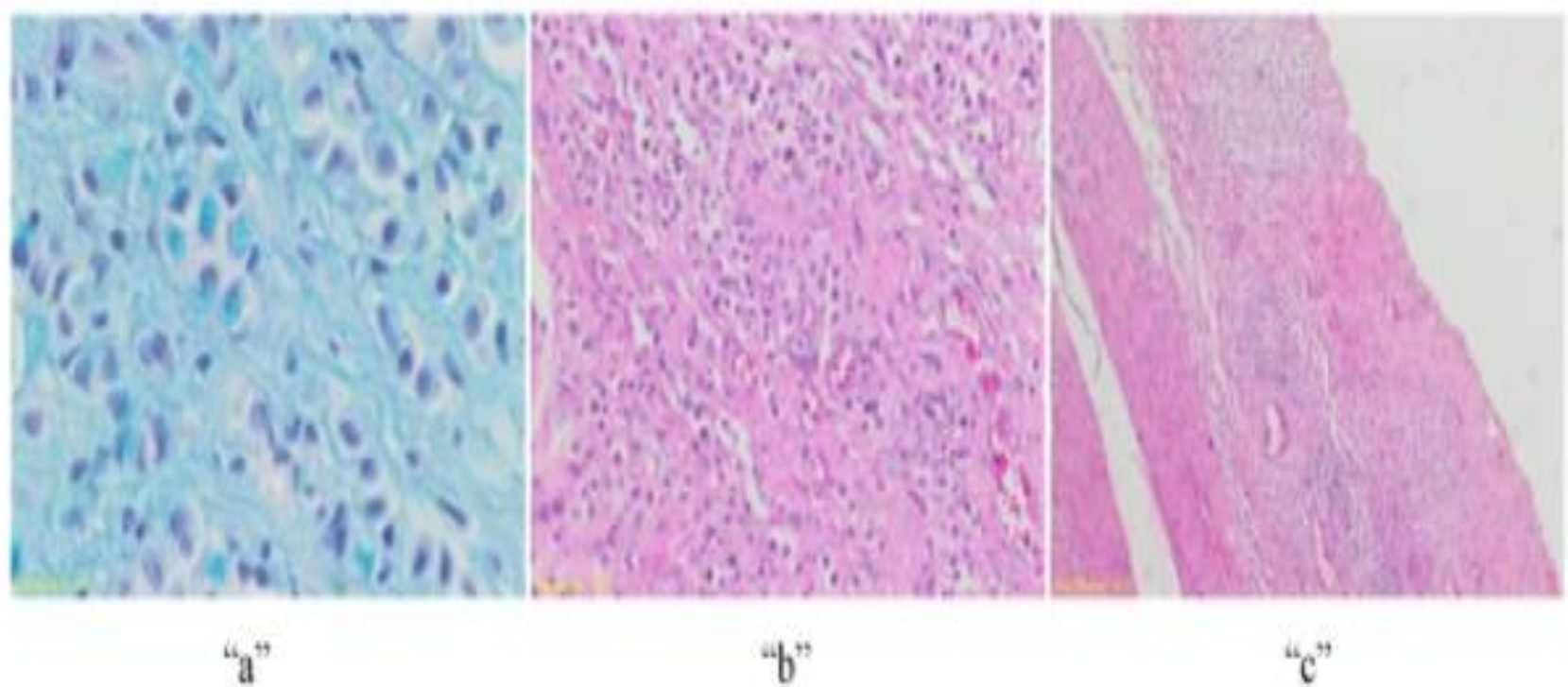

Figure 8: Multiple signet ring cells located in the lamina propria with overlying transitional cell epithelium (Alcian blue stainin " $a$ ", and Haematoxylin - eosin (HE) in "b" and "c". Reproiduced from: [46] Armache K, Feghali J, Bourgi A, Chemaly A K, Aftinos G, Moukarzel M. Pure primary signet ring cell carcinoma of the bladder: atypical case and review of the literature. Urology \& Nephrology Open Acces Journal. 2014; 1(3): 70 - 72. DOI:10.1504/unoaj.2014.01.00016 https://medcraveonline.com/UNOAJ/pure-primary-signet-ring-cell-carcinoma-of-the-bladder-atypicalcase-and-review-of-the-literature.html under Creative Commons Attribution License 


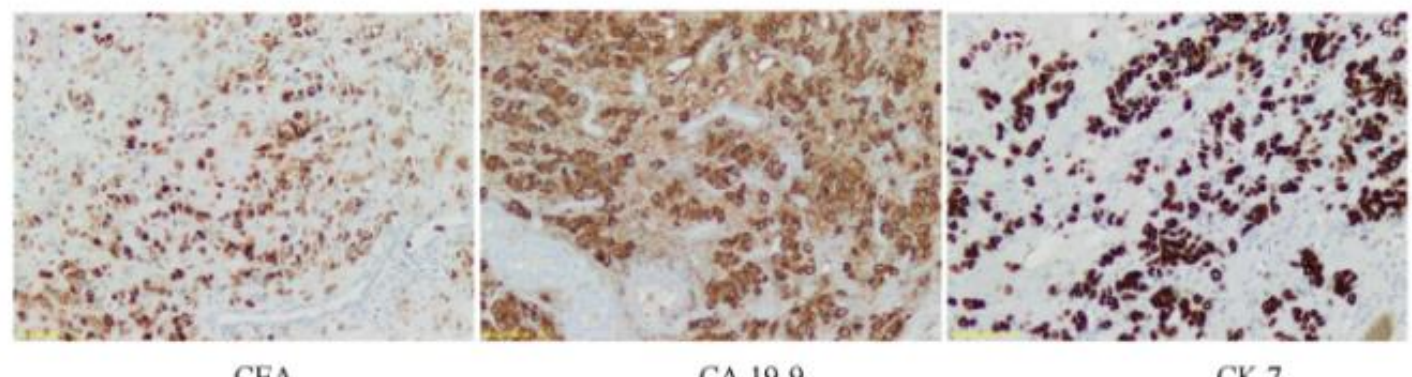

CEA

CA 19-9

CK 7

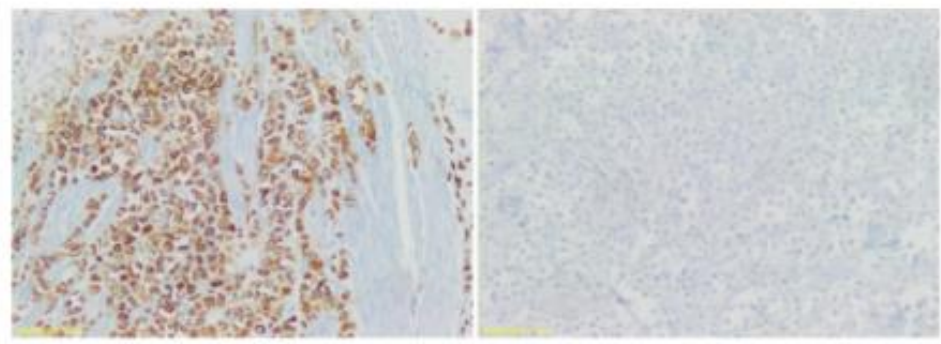

$\mathrm{CD} \times 2$

CK 20

\begin{abstract}
Figure 9: Immunohistochemical findings: IHC positive for CEA, CA 19 -9, CK 7, CK 20,; negative for CD X2. Reproduced from: [46] Armache K, Feghali J, Bourgi A, Chemaly A K, Aftinos G, Moukarzel M. Pure primary signet ring cell carcinoma of the bladder: atypical case and review of the literature. Urology \& Nephrology Open Acces Journal. 2014;1(3): 70 - 72. DOI:10.1504/unoaj.2014.01.00016

https://medcraveonline.com/UNOAJ/pure-primary-signet-ring-cell-carcinoma-of-the-bladder-atypical-case-and-review-of-the-literature.html under Creative Commons Attribution License.
\end{abstract}

Hirano et al. [47] reported a 65-year-old man who had presented with visible haematuria in November 1997. He had ultrasound scan of renal tract which showed left hydronephrosis. He had intravenous urography which demonstrated a non-functioning left kidney as well as a filling defect on his left bladder wall. He had computed tomography (CT) scan and magnetic resonance imaging (MRI) scan which showed left hydronephrosis and an invasive urinary bladder tumour but no evidence of distant metastasis. He underwent cystoscopy which showed a white, sessile tumour which had extended from the left wall of his urinary bladder to the trigone and which had obstructed the left ureteric orifice. Punch biopsy and trans-urethral resection of the tumour were undertaken. Histopathology examination of the specimens demonstrated that the tumour cells had formed abundant mucin and positive staining of cytoplasm by Periodic acid Schiff. A component of the tumour was noted to be high-grade transitional cell carcinoma. He underwent esophagogastroduodenoscopy and recto-sigmoidoscopy which did not demonstrate any tumour and had excluded a primary tumour from the gastrointestinal tract. A diagnosis of primary signet-ring cell carcinoma (PSRCC) of the urinary bladder T3BNOM0 was established. It was recommended that the patient should undergo radical cystectomy but the patient refused to undergo radical cystectomy. He received intra-arterial chemotherapy with utilization of Carboplatin. Angiography catheter was inserted via his left femoral artery into the left internal iliac artery near the branch of the vesical artery with utilization of Seldinger technique. The left superior gluteal artery was embolized to prevent necrosis of the hip by the carboplatin. $400 \mathrm{mg}$ of Carboplatin was instilled via the left catheter. Thereafter, $200 \mathrm{mg}$ of Carboplatin was instilled into the right vesical artery. Three courses of intra-arterial infusion of carboplatin were undertaken at 3 weeks intervals. One month pursuant to the completion of the treatment, he had computed tomography (CT) and magnetic resonance imaging (MRI) scans as well as cystoscopy and biopsy of the bladder which all demonstrated features that confirmed complete disappearance of the cancer. At the time of publication of the article the patient has had complete remission that had been maintained for 44 months with no evidence of local recurrence or metastasis.

Tagami et al. [48] iterated that primary signet-ring cell carcinoma of the urinary bladder is an uncommon tumour which has tended to be associated with poor prognosis. Tagami et al. [48] stated that there are few successful chemotherapy treatments for this tumour. Tagami et al. [48] reported a case of chemotherapy with a docetaxel regimen which did prove to be efficacious in a 64-year-old Japanese, who was suffering from signet-ring cell carcinoma of the urinary bladder. Tagami et al. [48] reported that the onset of bilateral hydronephrosis did lead to the detection of the urinary bladder tumour and pathology examination of the tumour showed features of signet-ring cell carcinoma of the urinary bladder. Immunohistochemistry staining studies of the tumour showed that the tumour cells had exhibited positive staining for cytokeratin $7+$, and cytokeratin $20+/$-. In view of the fact that the tumour had invaded the patient's abdominal wall and groin he could not be offered surgery but instead he was treated with utilization of chemotherapy. The patient initially received 2 courses of chemotherapy which did comprise of S-1 and cisplatin; nevertheless, this treatment was not effective. Tagami et al. [48] chose docetaxel as a second-line chemotherapy regimen which comprised of $60 \mathrm{mg} / \mathrm{m} 2$, tri-weekly, and his follow-up clinical examination and contrast-enhanced computed tomography demonstrated that his disease had successfully responded to the chemotherapy. Some lessons that can be learnt from this case summation include the following:

- $\quad$ Advanced and metastatic primary signet-ring cell carcinomas of the urinary bladder can be treated with curative intent with utilization of effective chemotherapy medicaments without surgery.

- $\quad$ There is the possibility that even though radical cystectomy has tended to be the treatment of choice for primary signet-ring cell carcinomas that are localized or locally advanced, these tumours could possibly be treated with utilization of trans-urethral resection of the bladder tumour plus multiple chemotherapy including docetaxel or other novel treatment options including trans-urethral 
resection of bladder tumour plus cryotherapy plus chemotherapy or selective angiography and super-selective embolization of the artery feeding the tumour plus chemotherapy, or radiofrequency ablation of the tumour plus radiotherapy plus chemotherapy with docetaxel, or trans-urethral resection of the tumour plus selective angiography plus super-selective chemo-embolization of the tumour directly with docetaxel.

- The lesson learnt from this case summation should encourage urologists, oncologists, and pharmacotherapy research workers to undertake studies that would identify new safe and effective chemotherapy agents that would safely and effectively destroy all primary and metastatic signet-ring cell carcinoma cells whether the tumours are primary or metastatic tumours.

\section{Summary and Conclusions}

- $\quad$ Signet-ring cell carcinoma of the urinary bladder (SRCCUB) is a rare aggressive malignant tumour which tends to be sporadically reported globally.

- $\quad$ Signet-ring cell carcinoma of the urinary bladder (SRCCUB) does affect males, females, adults and young ones.

- $\quad$ Signet-ring cell carcinoma of the urinary bladder (SRCCCUB) can be either primary or metastatic tumour with the primary tumour originating from elsewhere, particularly from the gastrointestinal tract.

- A high-index of suspicion is required to diagnose the disease based upon microscopy examination features of signet-ring tumour cells with nuclei that have been pushed to the periphery and evidence of mucin-filled vacuoles as well as positive immunohistochemistry staining of the tumour for: Cytokeratin, Vimentin, Peanut lectin agglutinin. Ulex europaeus agglutinin, and at times CDX2. Also there could be a small amount of positive staining for Villin. There tends to be negative staining for Vimentin, (this does show therefore in comparison with above some tumours would stain positive and others would stain negative), GATA3, p53.

- Majority of signet-ring cell tumours have tended to be reported as advanced high-stage tumours that tend to have poorer prognosis in comparison with conventional urothelial carcinoma.

- Diagnosis of primary or metastatic signet-ring cell carcinoma of urinary bladder does rely on a history taking of previous treatment for signet-ring cell carcinoma elsewhere and reviewing the pathology features of both tumours, the undertaking of radiology imaging and upper and lower gastrointestinal endoscopy plus biopsies of lesions that are found for pathology examination.

- In view of the poor prognosis of the tumour, an aggressive complete excision of the tumour plus aggressive adjuvant therapy including appropriate combination chemotherapy, radiotherapy, and immunotherapy should be regarded as treatment options of curative intent.

- Nevertheless, there is an anecdotal report of an effective treatment of an advanced metastatic primary signet-ring cell carcinoma of the urinary bladder with utilization of docetaxel which resulted in destruction of the tumour cells without an operation which would indicate that some chemotherapy agents could be good enough for the successful treatment of signet-ring cell carcinomas of the bladder including primary and metastatic tumours.

- There is need for new more safe and effective chemotherapy agents to be identified for the treatment of the tumour in order to improve the prognosis.

- A global multi-centre trial of different treatment options would be required to find the best treatment options for this aggressive disease.

\section{Conflict of interest - None}

\section{Acknowledgements -}

Acknowledgements to:

- Urology Case Reports for granting permission for reproduction of figures and contents of their journal article under creative Commons Agreement Licence.

- Case Reports in Urology and Hindawi Publishing for granting permission for reproduction of figures and contents of their journal article under creative Commons Agreement Licence.

- Urology \& Nephrology Open Access Journal for granting permission for reproduction of figures and contents of their journal article under creative Commons Agreement Licence.

\section{References}

1. Thomas D G, Ward A M, Williams J L. (1971) A study of 52 cases of adenocarcinoma of the bladder. Br. J. Urol; 43: 4-15

2. Saphir O. (1955) Signet-ring cell carcinoma of the urinary bladder. Am J. Pathol; 31: 223-231

3. Jung S, Jung S, Min K, Chung J -I, Choi S, Kang D. (2009) Primary Signet Ring Cell-Carcinoma of the Urinary Bladder. Korean Journal of Urology, 50(2): 188-191.

4. Wikipedia, the free encyclopedia, Signet ring cell carcinoma.

5. Benesh M, Mathieson A. (2020) Epidemiology of Signet Ring Cell Adenocarcinomas Cancer; 12(6): E1544 and PRSCC has tended to be encountered less frequently in the breast, gallbladder, urinary bladder, and pancreas.

6. Belli S, Aytac H O, Karagulle E; Yabanoglu H; Kayaselcuk F; Yildirim S. (2014) Outcomes of Surgical treatment of Primary Signet Ring Cell carcinoma of the Colon and Rectum: 22 Cases Reviewed With Literature. International Surgery. 99(6): 691698.

7. el-Zimaity H M, Itani K, Graham D Y. (1997) Early diagnosis of signet ring cell carcinoma of the stomach role of the Genta stain. J. Clin. Pathol; 50(10): 867-868.

8. Henson D E, Dittus C, Younes M, Nguyen H, Albores-Saavedra J. (2004) Differential Trends in the Intestinal and Diffuse Types of Gastric Carcinoma in the United States, 1973 - 2000: Increase in the Signet Ring Cell Type. Archives of Pathology \& Laboratory Medicine; 128(7): 765-770.

9. Shah R B,Zhou M. (2011) Prostate Biopsy Interpretation: An Illustrated Guide Springer Science \& Busines Media.

10. Shen S S, Zhai Q J, Ayala A G. (2012) Prostate Cancer Advances in Surgical Pathology. Lippincott Williams \& Wilkins.

11. Office of Rare Diseases Research: Diffuse Gastric cancer. National Institute of Health. National Institute of Health. pp. 8485

12. Muta H, Noguchi M, Kanai Y, Ochiai A, Nawata H, Hirohahashi S. (1996) E-Cadherin Gene Mutations in Signet Ring Cell Carcinoma of the Stomach. Japanese Journal of cancer Research; 87(8): 843-848.

13. Nakatsuru S, Yanagisawa A, Ichii S, Tahara E, Kato $\mathrm{Y}$, Nakamura Y, Horii A. (1992) Somatic mutation of the APC gene in gastric cancer: frequent mutations in very well differentiated adenocarcinoma and signet-ring cell carcinoma. Human Molecular Genetics.

14. Pernot S, Voron T, Perkins G, Lagorce-Pages C, Berger A, Taieb J. (2015) Signet-ring cell carcinoma of the stomach: Impact on prognosis and specific therapeutic challenge. World Journal of Gastroenterology. 21(40): 11428-11438.

15. Wikipedia, the free encyclopedia, Signet ring cell carcinoma. 
16. Fukui Y. (2014) Mechanisms behind signet ring cell carcinoma formation. Biochemical and Biophysical Research Communications. 450(4): 1231-1233.

17. Duarte I, Llanos O. Llanos O. (1981) Patterns of metastases in intestinal and diffuse types of carcinoma of the stomach. Human Pathology; 12(3): 237-242.

18. Iesato A, Oba T, Ono M, Hanamura T, Watanabe T, Ito K, Kanai T, Maeno K, Ishizaka K. (2014) Breast metastases of gastric signet-ring cell carcinoma: a report of two cases and review of the literature. Onco Targets and Therapy. 8: 91-97.

19. Portnoy L M. (2006) Radiologic Diagnosis of Gastric Cancer: A new Outlook. Springer Science \& Business Media.

20. Huh C W, Jung D H, Kim J-H, Lee Y C, Kim H, Kim H, Yoon S O, Youn Y H, Park H. (2013) Signet ring cell mixed histology may show more aggressive behavior than other histologies in early gastric. Journal of Surgical Oncology. 107(2): 124-129.

21. Hartman D J, Nikiforova M N, Chang D T, Chu E, Bahary N, brand R E, Zureikat A H, Zeh H J, Choudry H, Pai R K. (2013) Signet ring cell colorectal carcinoma: A distinct subset of mucinpoor microsatellite-stable signet ring cell carcinoma associated with dismal prognosis. The American Journal of Surgical Pathology; 37(7): 969-977.

22. Nitsche U, Zimmermann A, Späth Christoph, Müller Tara, Maak Matthias, Schuster T, Slotta-Huspenina J, Käser S A, Michalski W. (2013) Janssen K-P, Friess H, Rosenberg R,; Bader, F G. Mucinous and signet-Ring Cell Colorectal Cancers Differ from Classical Adenocarcinomas in Tumor Biology and Prognosis. Annals of Surgery; 258 (5): 775-783.

23. Dittus C, Mathew H, Malek A, Negroiu A. (2014) Bone marrow infiltration as the initial presentation of gastric signet ring cell adenocarcinoma. Journal of Gastrointestinal Oncology. 5 (6): E113-E116.

24. Signet Ring Cell Cancer / Oncolink - Cancer Resources

25. Pugashetti N, Yap S A, Lara P N, Gandour-Edwards R, Dall'Era $\mathrm{M}$ A. Metastatic signet-ring cell carcinoma of the urinary bladder: A novel approach to a rare tumour. Canadian Urological Association Journal. 201604 20; 9 (3-4): E204-E207.

26. Li, M., Vuolo, M., Weidenheim, K. et al. (2001) Collecting-Duct Carcinoma of the Kidney with Prominent Signet Ring Cell Features. Mod Pathol; 14, 623-628.

27. Takashi H, Yoshiyuki K, Taku N, Yasue K, Takahiro Y, Keiichi T, Yutaro H, Kenjiro K. (2013) Case Report: Long-Term Survival of a Patient with Invasive Signet-Ring Cell Carcinoma of the Urinary Bladder Managed by Combined S-1 and Cisplatin Adjuvant Chemotherapy. Case Reports in Urology. 2013 Apr; 915874.

28. Lee W S, Chun H K, Lee W Y, et al. (2007) Treatment outcomes in patients with signet ring cell carcinoma of the colorectum. The American Journal of Surgery. 194 (3): 294-298.

29. Kim J P, Kim S C, Yang H K. (1994) Prognostic significance of signet ring cell carcinoma of the stomach. Surgical Oncology. 3 (4): 221-227.

30. Kwon K-J; Shim K-N, Song E-M, Choi J-Y, Kim S-E, Jung HK, Jung S-A. (2013) Clinicopathological characteristics and prognosis of signet ring cell carcinoma of the stomach. Gastric Cancer.17 (1): 43-53

31. Fuyuhro Y, Yashiro M, Noda S, Kashiwagi S, Matsuoka J, Doi Y, Kato Y, Kubo N, Ohira M, Hirakawa K. (2010) Clinical significance of vimentin-positive Cancer cells. anticancer Research ; 30(12): 5239 - 5243

32. Ye, Z., Mi, Q., Luo, D. et al. (2020) a case report of primary upper urinary tract signet-ring cell carcinoma and literature review. BMC Urol. 20: 75.
33. Boukettaya W, Feki J, Charfi S, Toumi N, Khanfir A, Boudawara T, Daoud J, Frikha M. (2014) Primary Signet Ring Cell Adenocarcinoma of the Urinary Bladder: A Report of 2 Cases. Urology Case Reports. 2(3): 85-87.

34. Akamatsu S, Takahashi A, Ito M, Ogura K. (2010) Primary signet-ring cell carcinoma of the urinary bladder. Urology. 75(3):615-8. doi: 10.1016/j.urology.2009.06.065. Epub 2009 Oct 12. PMID: 19819534.

35. Bouhajja L, Farah F, Garbouj N, Rammeh S. (2019) Primary signet-ring cell carcinoma of the urinary bladder: A report of two cases. Tunis Med.97 (1):167-169. PMID: 31535712

36. Hamakawa T, Kojima Y, Naiki T, Kubota Y, Yasui T, Tozawa K, Hayashi Y, Kohri K. (2013) Long-term survival of a patient with invasive signet-ring cell carcinoma of the urinary bladder managed by combined s- 1 and Cisplatin adjuvant chemotherapy. Case Rep Urol. 2013:915874. Epub PMID: 23738191; PMCID: PMC3664482.

37. Wang J, Wang FW, Kessinger A. (2012) the impact of signetring cell carcinoma histology on bladder cancer outcome. World J Urol. 30(6):777-783. Epub 2011 Jun 25. PMID: 21706144.

38. Grignon DJ, Ro JY, Ayala AG, Johnson DE. (1991) Primary signet-ring cell carcinoma of the urinary bladder. Am J Clin Pathol.95 (1):13-20. doi: 10.1093/ajcp/95.1.13. PMID: 1702926.

39. El Ammari JE, Ahsaini M, Riyach O, El Fassi MJ, Farih MH, Hammas N, Elfatmi H, Amarti A. (2013) Primary signet-ring cell carcinoma of the urinary bladder successfully managed with cisplatin and gemcitabine: a case report. J Med Case Rep. 7:37.

40. Jin D, Qiu S, Jin K, Zhou X, Cao Q, Yang L, Wei Q. (2020) Signet-Ring Cell Carcinoma as an Independent Prognostic Factor for Patients With Urinary Bladder Cancer: A PopulationBased Study. Front Oncol.10:653.

41. Singh J, Zherebitskiy V, Gryngpain D, Czaykowski P M. (2012) Metastatic signet ring cell adenocarcinoma of the bladder: responsive to treatment? Can Urol. Assoc J. 6(1): E15 - E19.

42. Andreeva IuIu, Zavalishina LE, Maĭnovskaia OA, Bateva MV, Frank GA. (2007) [Signet-ring cell carcinoma of the bladder] Arkh Patol.69 (6):32-4. Russian. PMID: 18290378.

43. Matsuzaki A, Kobayashi Y, Suzuki K, Morita T, Tokue A. (2000) [Stage pT1 signet ring cell carcinoma of the urinary bladder: a case report]. Hinyokika Kiyo.46 (2):127-30. Japanese. PMID: 10769804.

44. Ozeki Z, Kobayashi S, Machida T, Ishizaka K, Oka T. [Transitional cell carcinoma of the urinary bladder accompanied by signet-ring cell carcinoma: a case report]. Hinyokika Kiyo. 2003 Jul;49(7):411-3. Japanese. PMID: 12968484.

45. Allameh F, Karkan M F, Nilipour Y, Rakhshan A. (2017) Primary Signet-Ring Cell Carcinoma of the Urinary Bladder Successfully Managed with Radical Cystectomy in a Young Patient. Case Reports in Urology. Article ID 9121078

46. Armache K, Feghali J, Bourgi A, Chemaly A K, Aftinos G, Moukarzel M. (2014) Pure primary signet ring cell carcinoma of the bladder: atypical case and review of the literature. Urology \& Nephrology Open Acces Journal;1(3): 70-72.

47. Hirano Y, Suzuki K, Fujita K, Furuse H, Fukuta K, Kitagawa M, Aso Y. (2002) Primary signet ring cell carcinoma of the urinary bladder successfully treated with intra-arterial chemotherapy alone. Urology.59 (4):601.

48. Tagami K, Tanda S, Satake Y, Takeuchi A, Abe Y, Namima T, Kusunose H, Muto M, Nagura H. (2012) [Successful chemotherapy with a docetaxel regimen for primary signet-ring cell carcinoma of the urinary bladder-a case report]. Gan To Kagaku Ryoho;39(11):1737-41. Japanese. PMID: 23152031. 